\title{
Aspiration-Attainment Gaps Predict Adolescents' Subjective Well-Being After Transition to Vocational Education and Training in Germany
}

\author{
Désirée Nießen ${ }^{\mathrm{a}}$, Alexandra Wicht ${ }^{\mathrm{b}, \mathrm{c}}$, and Clemens M. Lechner ${ }^{\mathrm{a}}$
}

\author{
${ }^{\mathrm{a} G E S I S ~-~ L e i b n i z ~ I n s t i t u t e ~ f o r ~ t h e ~ S o c i a l ~ S c i e n c e s, ~ M a n n h e i m, ~ G e r m a n y ~}$ \\ ${ }^{b}$ Federal Institute for Vocational Education and Training (BIBB), Bonn, Germany \\ ${ }^{c}$ University of Siegen, Department of Education \& Psychology, Germany
}

\begin{abstract}
Author Note
This research did not receive any specific grant from funding agencies in the public, commercial, or not-for-profit sectors. We have no competing interests to disclosure.

Correspondence concerning this article should be addressed to Désirée Nießen, GESIS - Leibniz Institute for the Social Sciences, P.O. Box 1221 55, 68072 Mannheim, Germany; e-mail: desiree.niessen@gesis.org.
\end{abstract}




\section{Highlights}

- Under- and overachievement of aspirations reduce subjective well-being on entry into vocational education and training

- During vocational education and training, subjective well-being increases more in those with an aspiration-attainment gap

- An occupational aspiration-attainment gap predicts income and job satisfaction more than general life satisfaction

- Crucial for well-being is not the status of the training position attained, but whether it is exactly the desired position 


\begin{abstract}
An occupational aspiration-attainment gap (AAG) is defined as a discrepancy between the socioeconomic status (SES) of the aspired and the attained occupation. We investigated how experiencing an occupational AAG after transition to vocational education and training (VET) affects three domains of subjective well-being (SWB)—namely, general life satisfaction, job satisfaction, and income satisfaction — among adolescents in Germany. Using longitudinal data from the German Socio-Economic Panel (SOEP), we could track respondents' SWB across their transition to VET and over a period of 1 to 2 years after VET entry. Results from latent growth curve models revealed that both under- and overachievement of aspirations reduced in particular initial levels of SWB (especially job satisfaction and income satisfaction) after VET entry. Strong discrepancies between aspirations and attainment $(A A G \leq|5|$ ISEI [International Socio-Economic Index of Occupational Status] score points) in particular led to higher dissatisfaction. Individuals with an AAG tended to experience a slightly larger increase in SWB during VET than those who met their aspirations. Overall, our results suggest that the decisive factor for adolescents' SWB is not the SES of the VET position they attain, but rather whether that position is the exact type of position to which they aspired, irrespective of whether the status of that occupation is lower or higher than the one they aspired to.
\end{abstract}

Keywords: aspirations, attainment, subjective well-being, school-to-work transition, vocational education and training (VET) 


\section{Introduction}

The occupational aspiration-attainment gap (AAG) refers to the discrepancy between the socio-economic status (SES) of occupational aspirations and attainment. Three groups of individuals can be distinguished: (a) those who fall short of their occupational aspirations, and experience a negative AAG (underachievement); (b) those who realize their occupational aspirations exactly; and (c) those who surpass their occupational aspirations, and experience a positive AAG (overachievement). AAGs are a widespread but unequally distributed phenomenon among adolescents in vocational education and training (VET) in Germany (e.g., Nießen et al., 2021). Previous studies have shown that, when accessing VET, young people have to make several compromises_-for example, in terms of qualification level, SES, career opportunities, job stability, and gender typicality (e.g., Ahrens et al., 2021b; Kleinert \& Scheels, 2020; Nießen et al., 2021).

But what are the consequences of experiencing an AAG? Although several scholars have argued that experiencing an $\mathrm{AAG}$ - at an early career stage - is likely to have unfavorable long-term consequences for career development (e.g., Nießen et al., 2021; Tomasik et al., 2009), only a few studies have investigated the extent to which occupational AAGs have negative consequences for individuals' subjective well-being (SWB; e.g., Carr, 1997; Hardie, 2014). The consequences of occupational AAGs for SWB are relevant both for individuals and for employers for two reasons. First, SWB is an important outcome in its own right. Second, SWB predicts, for example, work motivation (e.g., Ton \& Hansen, 2001), goal engagement (e.g., Luhman \& Hennecke, 2017), and goal striving (e.g., Haase et al., 2012). Low SWB is therefore a likely precursor of job dropout or occupational change (e.g., Giver et al., 2010) and other potentially detrimental career outcomes. Medici et al. (2020), for example, showed that individuals in Switzerland with higher VET satisfaction in the final phase of VET were more likely to work in their trained occupations, thus underscoring the importance of early formative experiences during VET for later, often costly, undesired job turnover. 
In addition to the scant evidence on the link between AAGs and SWB, little is known about the development of SWB in the event of an AAG. Studies have pointed to adaptive processes that occur even in the face of severe negative events and circumstances. For example, a meta-analysis conducted by Luhmann et al. (2012) found that a few years after losing their jobs, many people reached pre-unemployment levels of SWB. Similar patterns of adaptation have been found for non-work stressors such as filial bereavement (e.g., Leopold \& Lechner, 2015). However, longitudinal studies tracking SWB over time among individuals who have experienced an AAG are absent from the literature.

In the present study, we investigated the consequences of experiencing an AAG for SWB during the course of VET. Our study was guided by two research questions: (a) Does an occupational AAG lower young people's SWB when starting VET? (b) If so, does the SWB of apprentices decrease, increase, or remain the same over the course of VET as a function of this AAG? To answer these questions, we used representative longitudinal data from Germany tracking SWB among young people in VET for a period of 2 years.

\section{Theoretical Background}

\section{Consequences of Occupational AAGs for SWB and for Changes in SWB Over Time}

There are several relevant theories on the consequences of discrepancies between desired and actual states. They converge in the prediction that discrepancies between occupational aspirations and attainment will impair the SWB of young people in VET, whereas realizing or exceeding these aspirations will enhance SWB. The level of aspiration theory (e.g., Starbuck, 1963) assumes that an individual's level of aspirations serves as a reference point for their feelings of success and failure. Consequently, attainment that surpasses aspirations is perceived as success, whereas attainment that does not meet aspirations is perceived as failure. Similarly, multiple discrepancies theory (Michalos, 1985) asserts that SWB is a function of discrepancies (gaps) between what individuals have (attainment) and what they expected to have in the past or want for the future (aspirations). Self-discrepancy theory (Higgins, 1987) 
states that negative emotions depend on the type and magnitude of subjectively perceived discrepancies between the actual/own self-state (i.e., attainment, self-concept) and the ideal selfstate (i.e., aspirations, wishes), or between the actual/own self-state and the ought self-state (i.e., duties, responsibilities). It posits that actual-ideal discrepancies signify the absence of positive outcomes (i.e., the non-achievement of expectations), and are associated with feelings such as dissatisfaction and disappointment, whereas actual-ought discrepancies signify the presence of negative outcomes (i.e., the expectation of punishment), and are associated with feelings such as fear and restlessness.

Although these theories agree that discrepancies are generally detrimental to SWB, they do not explicitly consider changes in SWB over time while experiencing an (enduring) discrepancy. Individuals tend to return to a relatively stable baseline level of happiness after positive or negative life experiences - a phenomenon captured by the metaphor hedonic treadmill coined by Brickman and Campbell (1971), and also known as hedonic adaptation. Although these processes of adaptation vary among and within individuals (Diener et al., 2006), it is conceivable that the initially lower level of SWB in young people who have experienced an occupational AAG gradually returns to a baseline level similar to that of their peers who have not experienced an AAG.

\section{Previous Research on the Consequences of Occupational AAGs for SWB}

Little research has addressed the potential impact of occupational AAGs on SWB. In line with the theoretical perspectives discussed above, the few existing studies suggest that experiencing an occupational AAG leads to lower job satisfaction (Hardie, 2014), lower SWB (Carr, 1997), lower enjoyment of VET (Beckmann et al., 2021), more depressive symptoms (Carr, 1997; Hardie, 2014), and a decreased likelihood that individuals perceive themselves as "very successful" in their work lives (Carr, 1997).

Notably, evidence on the consequences of overachievement (i.e., attainment that exceeds aspirations) is contradictory. In a study on the consequences of unrealized occupational 
goals in the transition to adulthood conducted by Hardie (2014), overachievement was found to be associated with higher job satisfaction in one sample and with lower job satisfaction in another. A study examining the impact of occupational AAGs on women's mental health (i.e., depression, psychological well-being, and purpose in life) at midlife (Carr, 1997) found that there was no difference in mental health between those who had surpassed and those who had met their aspirations. Moreover, women who experienced a large positive occupational AAG were less likely to perceive themselves as "very successful" in their work lives than those who met their aspirations (Carr, 1997). In line with Kahneman and Tversky's (1979) classic dictum from prospect theory, "losses loom larger than gains" (p. 279), these inconsistent findings suggest that underachievement (i.e., experiencing a negative AAG) is more relevant to SWB than overachievement.

In addition to these few studies addressing the consequences of occupational AAGs for SWB, several studies have investigated educational AAGs (i.e., discrepancies between aspired and attained levels of education). Similar to the occupational AAG studies, Paat (2016) found that educational AAGs were linked to higher depressive symptoms among Mexican immigrant youth in the USA. Another study found that university-educated Canadians who worked in jobs for which they were overqualified had a significant risk of decline in self-rated health over a 4-year period (Smith \& Frank, 2005). By contrast, among secondary- or less-educated respondents, differences in occupational attainment were unrelated to differences in the risk of decline in self-rated health (Smith \& Frank, 2005). For the USA, Reynolds and Baird (2010) initially found that young adults who experienced an educational AAG had a greater risk of experiencing symptoms of depression — but only at the lowest level of aspirations (i.e., among those who failed to achieve a high school diploma). However, this apparent negative effect of an AAG on mental health disappeared when differences in depressive symptoms associated with educational attainment were additionally controlled for (Reynolds \& Baird, 2010). Likewise, a recent study of German adolescents did not find differences in 
life satisfaction between those who experienced an educational AAG and those who did not (Siembab \& Stawarz, 2019).

However, these studies investigated the consequences of an educational AAG and/or used samples from North America, mostly from the USA — sometimes comprising only women (Carr, 1997) or immigrants (Paat, 2016) — collected several decades ago (assessment of aspirations between 1975 and 1990). Moreover, they focused mostly on a different phase of life: aspirations at age 35 and attainment and dependent variables at age 53 (Carr, 1997); aspirations at age 14-22 and attainment and dependent variables at age 27-35 (Hardie, 2014). Thus, the findings of these few studies are not readily generalizable to the potential consequences for SWB of an early career AAG in the highly structured German school and VET system. In addition, these studies were mostly cross-sectional and did not investigate how SWB developed over time as a function of an AAG (for exceptions, see Siembab \& Stawarz, 2019; Smith \& Frank, 2005). Some of the studies also looked at quite different outcomes (e.g., [mental] health rather than SWB) or used only global measures of SWB. Because people may evaluate different domains of life differently, a comprehensive view of SWB should go beyond a global evaluation (Ruggeri et al., 2020) and examine individual domains of the construct. Consequently, further research is needed to close this gap.

\section{The Present Study}

Little is known about the impact of experiencing an occupational AAG on adolescents' SWB. The present study aimed to close this gap by tracing the development of SWB after the transition to VET among young people in Germany. For this purpose, we used representative longitudinal data from the Socio-Economic Panel on apprentices who had started their first VET position leading to a full vocational qualification. The data allowed us to track the SWB of adolescents over a period of 2 years (i.e., from VET entry until 2 years after VET entry). 
VET is an integral part of Germany's highly structured and stratified education system. Students typically enter VET after completing 9th or 10th grade at a vocationally oriented secondary school track, although other pathways are possible. The dual VET system provides initial vocational training before labor market entry (Protsch \& Solga, 2016). For an average of 3 years, apprentices learn the practical skills of a specific occupation at a company (on-the-job training) and, in parallel, take theoretical occupation-related and general subjects at a part-time vocational school (schooling; e.g., Heckhausen \& Tomasik, 2002). Different VET positions (i.e., low-skilled occupations such as baker, skilled occupations such as mechatronics technician, professional occupations such as bank clerk) require different schoolleaving qualifications, which are usually attained after different years of schooling. Because the VET system in Germany is vertically stratified, not all VET positions are equally accessible (Protsch \& Solga, 2016). As the transition from school to VET and from VET to the labor market is highly standardized, young people who have completed a certain VET program can typically only take up a job in that particular occupational field. Thus, because occupational upward mobility is very rare in Germany, a VET-related AAG-if not closed by switching to a different VET position — may often persist in later work life (Protsch \& Solga, 2016). This renders the German VET system an interesting case to study the consequences of occupational AAGs for SWB.

We considered three domains of SWB that are particularly relevant with regard to occupational attainment and further career development: general life satisfaction, job satisfaction, and income satisfaction. Although related, these three domains need not necessarily coincide. Recent studies (i.e., published after the year 2000) have reported correlations of similar magnitude between general life satisfaction and job satisfaction (e.g., $r=.30$ [Rode, 2004]; $r=.40$ [Rojas, 2007]), and between general life and income satisfaction (e.g., $r=.35$ [Zagórski, 2011]; $r=.41$ [Rojas, 2007]). Reported correlations between job satisfaction and income satisfaction have been generally somewhat higher (e.g., $r=.52$ [Rojas, 2007]; $r=.60$ [Sweet 
et al., 2006]). These findings suggest that when evaluating satisfaction with their lives in general, their jobs, and their income, individuals selectively consider information. Hence, examining the three domains of SWB separately provides a more nuanced picture of the consequences of an occupational AAG for SWB than considering only one domain or aggregating the three domains.

In the present study, we aimed to answer the following research questions: (a) Does experiencing an AAG impair initial levels of three domains of SWB (general life satisfaction, job satisfaction, income satisfaction) among young people when starting VET in Germany (i.e., the intercept of SWB)? (b) Does the SWB of apprentices decrease, increase, or remain the same over the course of VET as a function of the AAG (i.e., the slope of SWB)? We traced SWB over time (i.e., when starting VET and after 1 year and 2 years in VET), thereby enabling us to examine whether adolescents adapt to an AAG over time, and whether patterns of adaptation differ across individuals. To answer these questions, we analyzed two binary contrasts: underachievement versus perfect match, and overachievement versus perfect match.

We preregistered our hypotheses on a project web page on the Open Science Framework (OSF) website. ${ }^{1}$ Our hypotheses relating to the initial levels of SWB built on aspiration theory (Starbuck, 1963), multiple discrepancies theory (Michalos, 1985), and self-discrepancy theory (Higgins, 1987), which postulate that unrealized expectations are associated with lower SWB:

Hypothesis 1a: Underachievement compared to a perfect match between aspirations and attainment predicts lower initial levels of SWB.

Hypothesis 1b: Especially a large AAG (discrepancy between attainment and aspirations $\leq|5|)$ predicts lower initial levels of SWB.

${ }^{1}$ See https://osf.io/vzk92/?view_only=98c6b738fc044e37a72996c62db53786. 
Our hypotheses relating to changes in SWB over time were based on Brickman and Campbell's (1971) concept of the hedonic treadmill—also known as the process of "hedonic adaptation." We assumed that initially lower levels of SWB in young people who experienced an AAG gradually return to a baseline level similar to that of their peers who did not experience an AAG:

Hypothesis 2a: Underachievement compared to a perfect match between aspirations and attainment predicts a larger positive change in SWB over the course of VET.

Hypothesis 2b: A large AAG (discrepancy between attainment and aspirations $\leq|5|$ ) predicts a larger positive change in SWB.

In addition to testing our preregistered hypotheses, we conducted exploratory analyses concerning: (a) associations between the intercept (defined as the level of SWB at the initial observation time when starting VET) and the slope of SWB; (b) similarities and differences in the AAG-SWB associations across different indicators of SWB; and (c) the association between a positive AAG (i.e., overachievement) and SWB. Because previous findings regarding overachievement have been inconclusive, we refrained from formulating specific expectations in this regard. In additional analyses, and in an exploratory fashion, we defined the level of SWB reached at the last observation during VET as the intercept in order to find out whether experiencing an AAG is also a direct predictor of SWB in the final phase of VET.

When testing the potential effects of the AAG on SWB, we controlled for a set of possible confounding variables that prior research has found to be related to both the AAG and SWB, and that temporally precede the measurement of the AAG: the Big Five personality traits, sociostructural characteristics (parental SES, migration background, gender), year of entering VET, and VET entry before first interview. In Appendix A in the Supplementary Online Material, we present a summary of research findings regarding the association of these control variables with the AAG and SWB that highlights the need to consider these variables 
as potential confounders of the AAG-SWB interface. We expected our hypotheses to be confirmed both with and without control variables.

\section{Material and Methods}

\section{Dataset and Sample Description}

To answer the above-mentioned research questions, we used data from the German Socio-Economic Panel (SOEP; Goebel et al., 2019; version 35, https://doi.org/10.5684/soep$\underline{\text { core.v35). }} .{ }^{2}$ Conducted annually since 1984 , SOEP is an ongoing longitudinal survey of a representative sample now comprising almost 77,000 participants aged 16/17 years and older residing in over 40,000 private households in Germany. Because it covers a wide range of topics, such as occupational biographies, employment, earnings, health, and satisfaction indicators, SOEP is ideally suited to analyze consequences of the AAG for SWB.

The survey is refreshed annually with new 16/17-year-old adolescents from the surveyed households. At panel entry, these respondents complete the initial youth questionnaire, which is regularly updated and has included all variables relevant for our analyses since 2006, thereby resulting in a gross sample size of $N=6,073$. Thus, the first observations for respondents in our sample came from 13 different survey years (i.e., from 2006 to the last available survey year at the time the analyses were carried out, namely, 2018), and all other relevant variables and events such as school graduation also took place at different observation times. We combined these different observation times per respondent for our analyses.

\footnotetext{
${ }^{2}$ SOEP data are personal data that are subject to special protection in the European Union. The independent SOEP Survey Committee approves the SOEP questionnaire every year. In addition, SOEP is institutionally reviewed by the German Council for Social and Economic Data. Participation in the SOEP study is voluntary and based on the informed consent of participants in compliance with data protection legislation. Written informed consent to participate in this study is provided by the participants or, if aged under 18, by their legal guardians. To prevent harm to respondents, the data may be used only for the intended purpose (scientific research) and in an anonymized form. Therefore, access to the data is subject to conclusion of a data distribution contract (for details of access to SOEP data, visit: https://www.diw.de/en/diw_01.c.357906.en/soep_order_form_mod.html; for details of SOEP data protection measures, visit: https://www.diw.de/en/diw_01.c.601584.en/data_access.html).
} 
The number of available observations also varied among individuals as well as by outcome: For example, information on satisfaction with income was available for 10 survey years for some individuals and for only 2 survey years for others. For this reason, and consistent with our focus on SWB during VET, we considered only those survey years in which respondents were in VET. The observed VET episodes lasted at most 3 years for $95 \%$ of all respondents $\left(M=1.40\right.$ years $^{3}, S D=1.26$, Min. $=0$ years, Max. $=5$ years $)$. As mentioned in the pre-registration on the OSF website, we originally intended to cover the period between entry into VET and a maximum of 3 years after entry into VET. However, because the number of valid cases for SWB values 3 years after VET entry was too small (about 50) due either to VET dropout or panel dropout or to missing information, our analyses of SWB could cover only the period between VET entry and a maximum of 2 years after VET entry. The last column in Table 1 shows the number of persons for whom information was available for each outcome and the number of years during VET for which information was available.

Given the specific longitudinal data structure, we drew on data for all variables between 2006 and 2018, depending on the phase that the respondents were in: Information on personality traits, sociostructural characteristics, and occupational aspirations was collected with the initial youth questionnaire when the respondents were aged 16/17 years and most of them were still at school, and hence before entry into VET. We gathered information on the VET position attained and the year of entering VET for the time when respondents entered VET and after school graduation $\left(\mathrm{t}_{0}\right)$. We gathered information on the consequences of the AAG for SWB for the year of VET entry $\left(t_{0}\right)$ and 1-2 years after VET entry $\left(t_{1}-t_{2}\right)$. We gathered information on general life satisfaction additionally for the year before VET entry $\left(\mathrm{t}_{-1}\right)$. Table 1 displays the descriptive statistics of all measures in the present sample. Appendix B in

\footnotetext{
${ }^{3}$ The average observed VET duration did not necessarily correspond to the actual VET duration either because of missing data or because of survey dropout from a certain point in time.
} 
the Supplementary Online Material displays the correlations between SWB and all other variables.

\section{Table 1}

Descriptive Statistics of all Measures

\begin{tabular}{|c|c|c|c|c|c|c|}
\hline Continuous variables & Min. & Max. & $M$ & $S D$ & Valid $N$ & Missings \\
\hline \multicolumn{7}{|l|}{ General life satisfaction } \\
\hline 1 year before VET & 1 & 10 & 7.62 & 1.59 & 1,141 & 395 \\
\hline When starting VET & 0 & 10 & 7.73 & 1.60 & 1,089 & 447 \\
\hline After 1 year in VET & 0 & 10 & 7.58 & 1.55 & 815 & 721 \\
\hline After 2 years in VET & 0 & 10 & 7.37 & 1.63 & 437 & 1,099 \\
\hline \multicolumn{7}{|l|}{ Job satisfaction } \\
\hline When starting VET & 0 & 10 & 7.92 & 1.87 & 703 & 833 \\
\hline After 1 year in VET & 0 & 10 & 7.53 & 2.04 & 784 & 752 \\
\hline After 2 years in VET & 0 & 10 & 7.27 & 2.07 & 423 & 1,113 \\
\hline \multicolumn{7}{|l|}{ Income satisfaction } \\
\hline When starting VET & 0 & 10 & 5.98 & 2.68 & 772 & 764 \\
\hline After 1 year in VET & 0 & 10 & 6.05 & 2.54 & 807 & 729 \\
\hline After 2 years in VET & 0 & 10 & 5.74 & 2.46 & 435 & 1,101 \\
\hline \multicolumn{7}{|l|}{ AAG-related variables } \\
\hline Aspirations & 16 & 88 & 43.71 & 14.66 & 1,265 & 271 \\
\hline Attainment & 16 & 60 & 39.56 & 10.45 & 997 & 539 \\
\hline Aspiration-attainment gap & 32 & -63 & -4.26 & 12.25 & 726 & 810 \\
\hline \multicolumn{7}{|l|}{ Big Five $^{a}$} \\
\hline Extraversion & 1.0 & 7.0 & 4.90 & 1.25 & 1,516 & 20 \\
\hline Agreeableness & 1.0 & 7.0 & 5.35 & 0.93 & 1,519 & 17 \\
\hline Conscientiousness & 1.0 & 7.0 & 4.95 & 1.10 & 1,521 & 15 \\
\hline Emotional Stability & 1.0 & 7.0 & 4.05 & 1.14 & 1,524 & 12 \\
\hline Openness & 1.5 & 7.0 & 4.64 & 1.00 & 1,506 & 30 \\
\hline Parental SES & 11.74 & 88.31 & 42.44 & 18.63 & 683 & 853 \\
\hline \multicolumn{7}{|l|}{ Process time in months between } \\
\hline \multicolumn{7}{|l|}{ VET entry and $t_{0}$ for } \\
\hline General life satisfaction & 0 & 10 & 5.15 & 3.01 & 1,089 & 447 \\
\hline Job satisfaction & 0 & 10 & 6.15 & 2.71 & 703 & 833 \\
\hline Income satisfaction & 0 & 10 & 5.98 & 2.80 & 772 & 764 \\
\hline \multicolumn{7}{|l|}{ VET entry and $t_{1}$ for } \\
\hline General life satisfaction & 9 & 26 & 17.04 & 3.41 & 815 & 721 \\
\hline Job satisfaction & 9 & 26 & 17.09 & 3.41 & 784 & 752 \\
\hline Income satisfaction & 9 & 26 & 17.04 & 3.41 & 807 & 729 \\
\hline \multicolumn{7}{|l|}{ VET entry and $t_{2}$ for } \\
\hline General life satisfaction & 18 & 39 & 28.79 & 3.52 & 437 & 1,099 \\
\hline Job satisfaction & 18 & 39 & 28.77 & 3.50 & 423 & 1,113 \\
\hline Income satisfaction & 18 & 39 & 28.78 & 3.53 & 435 & 1,101 \\
\hline
\end{tabular}

(continued) 
Table 1 (continued)

\begin{tabular}{|c|c|c|c|c|c|c|}
\hline \multicolumn{3}{|l|}{ Categorical variables } & \multicolumn{2}{|c|}{$\%$ (incl. missings) } & \multirow[t]{2}{*}{$N$} & \multirow{2}{*}{$\begin{array}{r}\text { Missings } \\
810\end{array}$} \\
\hline Dummy AAGs (0) & & & 52,7 & & & \\
\hline Perfect match $(\mathrm{AAG}=0)$ & - & - & 24.8 & - & 380 & - \\
\hline Underachievement $(\mathrm{AAG}<0)$ & - & - & 15.6 & - & 240 & - \\
\hline Overachievement $(\mathrm{AAG}>0)$ & - & - & 6.9 & - & 106 & - \\
\hline Dummy AAGs (+/-5) & & & 52.7 & & & 810 \\
\hline Perfect match $(\mathrm{AAG} \leq|5|)$ & - & - & 30.0 & - & 461 & - \\
\hline Underachievement $(\mathrm{AAG}<-5)$ & - & - & 13.0 & - & 199 & - \\
\hline Overachievement (AAG > 5) & - & - & 4.3 & - & 66 & - \\
\hline Migration background & & & & & & 0 \\
\hline No & - & - & 81.0 & - & 1,245 & - \\
\hline Yes & - & - & 19.0 & - & 291 & - \\
\hline Gender & & & & & & 0 \\
\hline Male & - & - & 54.8 & - & 841 & - \\
\hline Female & - & - & 45.2 & - & 695 & - \\
\hline Year of entering VET & & & & & & 0 \\
\hline Pre-economic crisis (2006-2009) & - & - & 21.3 & - & 327 & - \\
\hline Post-economic crisis recovery (2010-2013) & - & - & 33.8 & - & 520 & - \\
\hline Normalcy (2014-2018) & - & - & 44.9 & - & 689 & - \\
\hline VET entry before first interview & & & & & & 0 \\
\hline After first interview & - & - & 76.7 & - & 1,178 & - \\
\hline Before first interview & - & - & 23.3 & - & 358 & - \\
\hline
\end{tabular}

Note. $\mathrm{AAG}=$ aspiration-attainment gap, ISEI = International Socio-Economic Index of Occupational Status, SES = socioeconomic status, VET = vocational education and training.

${ }^{\text {a }}$ We recoded the negatively keyed items ( $\left.y_{\text {recoded }}=8-y_{\text {original }}\right)$ before computing the unweighted mean score of the Big Five dimensions.

We excluded (a) respondents whose last observed episode was a school episode - that is, who dropped out of the panel after school graduation—(leading to $N=5,496$ ); (b) respondents for whom no information on the time of school graduation was available (leading to $N=4,104$ ); (c) respondents who never entered VET (leading to $N=1,928$ ); (d) respondents with inconsistent data (e.g., the VET episode began prior to school graduation; leading to $N=1,858$ ); (e) respondents who completed VET before the first survey (leading to $N=1,804$ ); and (f) respondents for whom neither information on aspirations, attainment, nor on a single dependent variable was available (resulting in a total $N$ of 1,536 respondents). 
The average age of respondents at the time of school graduation was 16.97 years $(S D=1.43$, Min. $=14$, Max. $=22)$. Respondents graduated with different school-leaving certificates: (a) basic school-leaving qualification (29.6\%; German: Hauptschulabschluss; International Standard Classification of Education [ISCED-97] Level 2B); (b) intermediate schoolleaving qualification (46.0\%; German: Mittlere Reife; ISCED-97 Level 2A); (c) entrance qualification for a university of applied sciences (6.7\%; German: Fachhochschulreife; ISCED-97 Level 3A); and (d) general higher education entrance qualification (17.73\%, German: Abitur; ISCED-97 Level 3A; for an overview of the ISCED-97 levels in the German education system, see Schneider, 2008).

\section{Measures}

\section{Main Predictor: Aspiration-Attainment Gap (AAG)}

To operationalize the AAG, we calculated the difference score between the SES of the occupation in which an apprenticeship was obtained after VET entry and the SES of the occupation aspired to before VET entry. SES was measured in terms of the ISEI scores (International Socio-Economic Index of Occupational Status; Ganzeboom et al., 1992) associated with the corresponding occupation. As a metric variable, the AAG can have a negative value (aspirations higher than attainment; $\mathrm{AAG}<0$; i.e., underachievement), a positive value (aspirations lower than attainment; $\mathrm{AAG}>0$; i.e., overachievement), or the value zero (aspirations equal to attainment; $A A G=0)$. We computed two dummy variables, and used them to compare, first, underachievement (1) and, second, overachievement (2) with the reference category perfect match (0). Besides the dummies with a zero threshold (i.e., underachievement: AAG $<0$, overachievement: $\mathrm{AAG}>0$, perfect match: $\mathrm{AAG}=0$ ), we computed two further dummy AAGs with the threshold of $|5|$ - that is, AAG values between -5 and +5 were not as- 
signed to underachievement or overachievement but to the category perfect match. We compared the effects of these two different AAG thresholds on SWB in order to find out whether only a certain magnitude of AAG affects SWB. ${ }^{4}$

In SOEP, occupational aspirations are measured in two steps. At the age of 16/17, the respondents are asked whether they had an occupational aspiration: "Do you already know what occupation you want to take up?" (our literal translation of "Wissen Sie schon, welchen Beruf Sie ergreifen möchten"; for the freer SOEP translation ["Do (you) have a career aspiration?'], see SOEP Group, 2020b, p. 24). If this question is answered in the affirmative, the aspired occupation is measured with the open question "What kind of occupation is that? Please state as exact[ly] as possible." (SOEP Group, 2020b, p. 24). Occupational attainment is assessed annually with the open question "What is your current position/occupation? Please state the exact title in German. [...] If you are an apprentice or in vocational training, please state the occupation for which you were trained." (SOEP Group, 2020a, p. 22).

The answers are coded into various standard occupation classification schemes. As a typical measure of SES, and consistent with some earlier studies (e.g., Nießen et al., 2021), we decided to use ISEI scores. ISEI takes into account the educational level that a specific occupation requires and the income of that occupation (Züll, 2016). Scores range from 11.56 (low), representing gardeners, to 88.96 (high), representing judges.

If respondents' attainment values represented occupations that cannot be attained without tertiary education (ISEI scores above 64), we set the value on this variable to "missing." We presumed that these improbable attainment values were due to either completion (e.g., inconsistent response behavior) or coding errors. If there was a missing value for attainment when starting a VET position, we chose the attainment value from the year after VET entry and controlled for the duration of the VET episode - that is, we filled attainment values

\footnotetext{
${ }^{4}$ Note that we could not investigate further thresholds, for example, of $|10|$ because the number of valid cases would have become too small.
} 
only if we could be certain that respondents had not switched to a different VET position or to employment. We continued this procedure if there were also missing values for the year after entry into VET, and so forth, controlling each time for the duration of the VET episode.

\section{Dependent Variables}

Our focus was on the consequences of the AAG for respondents' SWB. We considered these consequences for three domains of SWB (general life satisfaction, job satisfaction, and income satisfaction), which although correlated to a certain extent are independent of each other (for more information, see Appendix C in the Supplementary Online Material).

In SOEP, current general life satisfaction, job satisfaction, and income satisfaction are surveyed annually with the questions "How satisfied are you with your life, all things considered?” (SOEP Group, 2020a, p. 73); “How satisfied are you with your job?” (SOEP Group, 2020a, pp. 4-5); and "How satisfied are you with your personal income?" (SOEP Group, 2020a, pp. 4-5) on a response scale ranging from 0 (completely dissatisfied) to 10 (completely satisfied). As Appendix B in the Supplementary Online Material shows, although the three satisfaction domains are correlated to some extent $(.30 \leq r \leq .36)$ at the same observation time after VET entry, they are not interchangeable measures.

In the present study, we used information on the satisfaction variables from the year that respondents entered VET until up to 2 years after VET entry. When doing so, we controlled for the duration of the VET episode, and we used information on, for example, job satisfaction after 2 years in VET only if we could be certain that respondents had not switched to a different VET position or to employment when job satisfaction was assessed. It is noteworthy that there were a substantial number of missing values especially for the job satisfaction and income satisfaction variables at the time when starting a VET position (see Table 1). This was due either to the fact that the respondents did not provide information on satisfaction (i.e., item missingness) or that respondents' VET episode began in the year of panel entry, be it be- 
fore the survey or after the survey (so that the question about job satisfaction and income satisfaction was not asked). Job satisfaction and income satisfaction are not surveyed in the initial youth questionnaire(SOEP Group, 2020b) but rather in the subsequent questionnaire administered to each eligible member of the household, which respondents receive for the first time 1 year after panel entry (SOEP Group, 2020a).

\section{Time-Invariant Control Variables}

We included the measures described below in the analyses as potential confounding variables for the AAG and its consequences. All these variables were measured prior to entry into VET.

Big Five Personality Traits. Since 2006, the 15-item Big Five Inventory-SOEP (BFIS; Schupp \& Gerlitz, 2014) and one additional item for Openness have been used to measure the Big Five personality traits in all 16/17-year-olds when they complete the youth questionnaire for the first time. The dimensions Extraversion, Agreeableness, Conscientiousness, and Emotional Stability are assessed with three items each, whereas Openness is assessed with four items in order to capture this dimension more broadly. The items are answered using a 7point rating scale that ranges from 1 (strongly disagree) to 7 (strongly agree). BFI-S has satisfactory psychometric properties (e.g., Schupp \& Gerlitz, 2014). In the present study, the internal consistencies of the dimensions ranged between Cronbach's alpha $=.45$ (Agreeableness) and .72 (Extraversion), which can be deemed sufficient for short scales (e.g., Aiken \& GrothMarnat, 2006). We used each respondent's first available Big Five scores before they entered VET.

Sociostructural Characteristics. To assess respondents' sociostructural characteristics, we used parental SES, migration background, gender, and age.

In SOEP, parental SES is assessed with the open question "What [is your father's/mother's position/occupation or what] was your father's/mother's last occupation?" (SOEP Group, 2020b, p. 36). The answers are coded into standard occupational classification 
schemes, such as the International Standard Classification of Occupations (ISCO; International Labour Office, 1990), ISEI (Ganzeboom et al., 1992), and the Standard International Occupational Prestige Scale (SIOPS; Ganzeboom \& Treiman, 2003; Treiman, 1977). To keep the classification between parental SES and occupational aspirations equivalent, we used ISEI scores. In cases where the mother's and father's ISEI scores differed, we used the higher score. We coded migration background as 0 (no) versus 1 (yes) based on information about the respondent's country of birth and citizenship. The gender of the respondent was coded as 0 (male) or 1 (female).

Year of VET Entry. The year of entering VET varied among respondents and ranged between 2006 and 2018. This variable was included in the analyses to compensate for seasonal effects (e.g., of the economy or the labor market). For this purpose, we combined between 4 and 5 sequential years in order to represent three different phases: 2006-2009 (preeconomic crisis), 2010-2013 (post-economic crisis recovery), and 2014-2018 (normalcy). We tested two binary contrasts: 2014-2018 normalcy (0; reference category) versus 2010-2013 post-economic crisis recovery (1), and 2014-2018 normalcy (0) versus 2006-2009 pre-economic crisis (1).

VET Entry Before First Interview. We included the binary variable VET entry before first interview in the analyses to compensate for potential causal effects because some respondents had already started a VET position before their first interview — that is, before all other independent variables had been collected. We coded the variable as 0 (no) versus 1 (yes).

\section{Time-Varying Control Variable Process Time}

We included the process time in months between VET entry and $t_{0}$, between VET entry and $t_{1}$, and between VET entry and $t_{2}$ in the analyses because the time that elapsed between the single observations differed among respondents. 


\section{Analyses}

\section{Main Analyses}

Using Mplus version 8.4 (Muthén \& Muthén, 1998-2017), we applied conditional latent growth curve (LGC) modeling to analyze the relationships between the AAG, the control variables, and both the initial level of SWB and changes in SWB during VET. LGC modeling allowed us to analyze the systematic intra-individual changes in repeated measures over time, on the one hand, and inter-individual differences in these changes, on the other. LGC models predict the random intercept (i.e., the initial level) and the random linear slope (i.e., mean growth rate of change) by means of other (time-invariant and/or time-varying) covariates (conditional LGCs). In this way, we can explain in more detail why some individuals experience a certain type of change in SWB and why others do not. We defined the initial observation time when starting VET $\left(\mathrm{t}_{0}\right)$ as the intercept. This allowed us to predict the initial level of SWB (i.e., the intercept) after entry into VET as well as the change in (i.e., the slope of) SWB during the course of VET over a period of 2 years $\left(t_{0}-t_{2}\right.$; i.e., when starting VET to $1-2$ years in VET) over these initial levels.

For each dependent variable (i.e., general life satisfaction, job satisfaction, and income satisfaction), we ran the following analyses: In the first step, we modeled an unconditional LGC model without predictors (Model I) to test how well a LGC model fit the data. In the second step, we used the two AAG dummy variables as manifest time-invariant predictors of SWB (Model II) to examine whether there was an effect of AAG on SWB, thereby using the auxiliary option to identify the missing data correlates of aspirations and attainment in addition to the analysis variables (see Muthén \& Muthén, 1998-2017). In the third step, we conducted further analyses that additionally included the control variables as manifest time-invariant predictors (Model III) to investigate whether these variables changed the effect of AAG 
on SWB..$^{5}$ A schematic depiction of the most complex model with predictor variables is displayed in Appendix E in the Supplementary Online Material.

We computed Models II-IV twice: first, with the two dummy AAG variables with the threshold of zero with underachievement as AAG $<0$, overachievement as AAG $>0$, and perfect match as $A A G=0$. Second, we used the two dummy AAG variables with the threshold of $|5|$ with underachievement as $\mathrm{AAG}<-5$, overachievement as $\mathrm{AAG}<5$, and perfect match as $-5 \leq \mathrm{AAG} \leq 5$. We compared the effects of these two different AAG thresholds on SWB to find out whether a large AAG $(\leq|5|)$ affected SWB more than the more conservative computation of an AAG $(<0)$.

We modeled the LGCs in a linear fashion with fixed time scores (i.e., loadings of the slopes) of $0\left(t_{0}\right), 1\left(t_{1}\right)$, and $2\left(t_{2}\right)$. The loadings of the intercepts of the three observation times of each SWB domain were 1. We used maximum likelihood estimation with robust standard errors (MLR) and restricted all latent variances (i.e., of the intercept and slope) to be positive defined. The variances of the independent variables were modeled as free parameters to be estimated using default starting values. Furthermore, we used full information maximum likelihood (FIML) estimation in our analyses to handle missing values on single items (unit nonresponse and item nonresponse). Prior to the analyses, we recoded negatively keyed items, such as reversed Big Five items. ${ }^{6}$

\footnotetext{
${ }^{5}$ For the prediction of general life satisfaction only, in the fourth step, we included pre-VET general life satisfaction at $\mathrm{t}_{-1}$ as additional manifest predictor (Model IV) to control for unobserved heterogeneity. The model estimates are reported in Appendix D in the Supplementary Online Material.

${ }^{6}$ The following points differed from the pre-registration: (a) Instead of focusing on the period between VET entry and a maximum of 3 years after VET entry, we focused on the period between VET entry and a maximum of 2 years after VET entry because valid cases for SWB values 3 years after VET entry were too small (about 50). (b) Instead of using the difference score on the metric AAG variable, we used two sets of dummy AAG variables with different AAG thresholds ( 0 and $|5|)$ and compared the effects of these two thresholds on SWB because the sample sizes and variances within the group of AAG $<0$ and AAG $>0$ were too small. (c) We did not center the continuous independent variables. (d) We did not control for cognitive ability, because cognitive ability has not been shown to be a confounding variable of the AAG in previous research (e.g., Nießen et al., 2021).
} 


\section{Sensitivity Analyses}

Because the elapsed (i.e., process) time between the single observations differed among respondents, we computed all models (i.e., Models I-III and I-IV, respectively) a second time as robustness checks, while including the process time variables as manifest timevarying predictors of SWB, thereby assigning the elapsed time to each measurement occasion of SWB as depicted in Appendix E in the Supplementary Online Material. The results of these sensitivity analyses fully confirmed those of the main analyses reported below and are available upon request.

\section{Results}

\section{Depiction of the AAG}

\section{Figure 1}

Percentages of the Distribution of the Aspiration-Attainment Gap

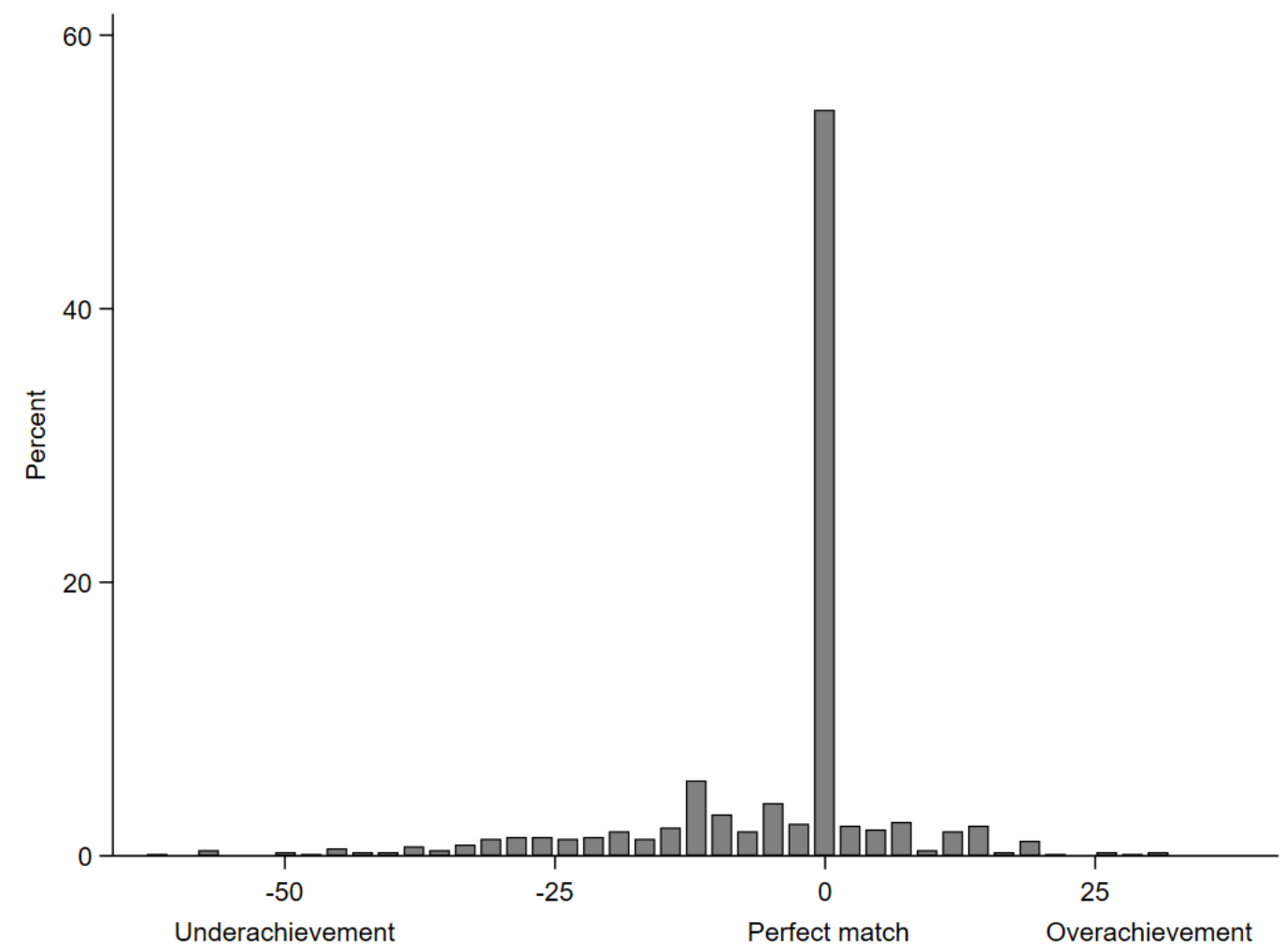

Note. As a metric variable, the peak in the middle includes both the zeros and a few additional observations with values close to zero. $N=726$. 
As Figure 1 shows, for the proportion of the sample for which both an aspiration and an attainment value were available (about 50\%), the ISEI score of the attained VET position perfectly matched the ISEI score of their aspired occupation in $52.3 \%$ cases - that is, these respondents fully realized their aspirations in terms of SES. In $14.6 \%$ of cases, respondents even surpassed their aspirations by attaining VET positions with ISEI scores that were up to 32 points higher than that of their aspired occupations (i.e., overachievement). By contrast, $33.1 \%$ of respondents fell short of their aspirations and attained VET positions with ISEI scores that were up to 63 points lower than that of their aspired occupations (i.e., underachievement). The percentages of the distribution of the components of the AAG (i.e., aspirations and attainment) can be found in Appendix F in the Supplementary Online Material.

\section{Prediction of the Initial Level of and Change in SWB}

We started by regressing the initial level (i.e., intercept) and the mean growth rates of change (i.e., linear slope) of three domains of SWB (general life satisfaction, job satisfaction, and income satisfaction) on the predictor variables.

\section{Unconditional Model (Model I)}

The first model we analyzed was the unconditional LGC model without predictors (Model I). The model results are displayed in Table 2. According to the benchmarks proposed by $\mathrm{Hu}$ and Bentler (1999), this basis model showed a very good model fit for all dependent variables: general life satisfaction- $-\chi^{2}(1)=0.004, p=.948$, comparative fix index $(\mathrm{CFI})=1.000$, root-mean-square error of approximation $(\mathrm{RMSEA})=.000$, standardized rootmean-square residual $(\mathrm{SRMR})=.001$, Bayesian information criterion $(\mathrm{BIC})=8,592.899 ;$ job satisfaction- $\chi^{2}(1)=1.397, p=.237, \mathrm{CFI}=.997, \mathrm{RMSEA}=.019, \mathrm{SRMR}=.012$, $\mathrm{BIC}=7,864.152 ;$ income satisfaction $-\chi^{2}(1)=0.323, p=.570, \mathrm{CFI}=1.000, \mathrm{RMSEA}=.000$, $\mathrm{SRMR}=.005, \mathrm{BIC}=9,208.292$.

Although the intercept-slope covariance was significant only for income satisfaction, job satisfaction and general life satisfaction tended in the same-namely, negative- direction. 
This negative intercept-slope covariance in connection with a negative slope in all SWB domains showed that higher initial levels of SWB were related to up to 1.2 scale points steeper declines, or more decline over time, and lower initial levels of SWB were related to slower declines, or a less steep negative slope.

\section{Table 2}

Unstandardized Coefficients of the Unconditional Latent Growth Curve Models (Model I)

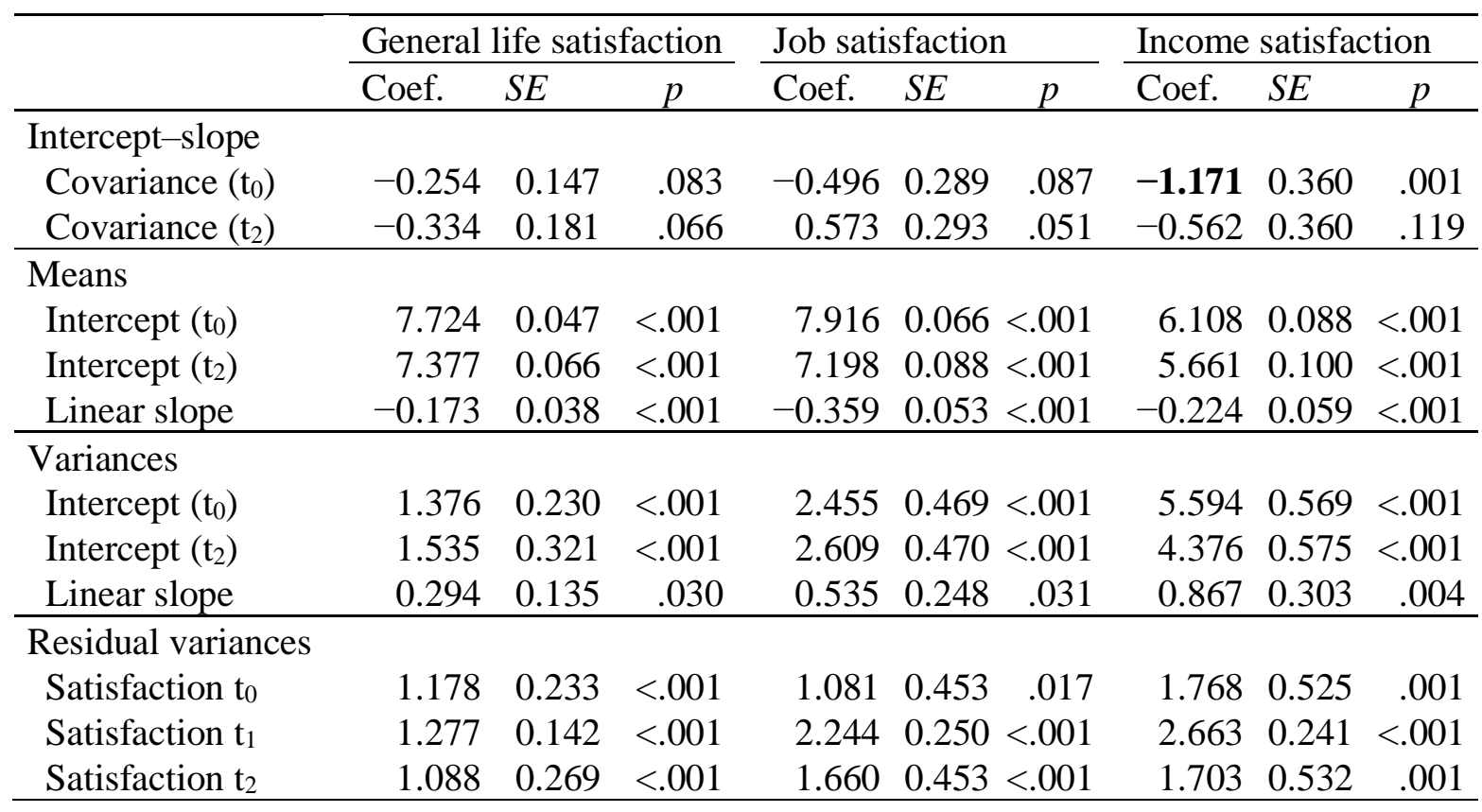

Note. $N_{\text {life }}=1,209 ; N_{\text {job }}=1,047 ; N_{\text {income }}=1,101$. Intercept-slope covariances significant at the $p<.05$ level are in bold type.

\section{The AAG Predicting SWB (Model II)}

The second model we analyzed was the conditional LGC model with the two dummy AAGs as predictors (Model II). The model results are displayed in a table in Appendix G in the Supplementary Online Material. As shown in that table, both underachievement and overachievement were statistically significant predictors of lower levels of general life satisfaction and job satisfaction after VET entry (i.e., the intercept) in the case of the AAG threshold of zero, thus confirming Hypothesis 1a, which states that underachievement compared to perfect match predicts lower initial levels of SWB. This finding means that a negative and a positive AAG (i.e., underachievement and overachievement of occupational aspirations in terms of 
SES) were associated with $0.3-0.5$ lower initial levels of general life satisfaction and $0.3-0.7$ lower initial levels of job satisfaction. In the case of the AAG threshold of $|5|$, the effect of underachievement remained about the same, whereas the effect of overachievement decreased slightly and was no longer significant. However, overachievement still showed larger negative effects on the initial level of SWB than underachievement—namely, -0.4 scale points for general life satisfaction and -0.6 scale points for job satisfaction.

Income satisfaction showed a different picture: The negative significant effect of underachievement on the intercept in the case of the zero threshold even increased in the case of the $|5|$-threshold, thus confirming Hypothesis $1 \mathrm{~b}$ and indicating that falling short of occupational aspirations by at least 5 ISEI score points (i.e., a large AAG) was associated with 0.9 lower scale points in income satisfaction. Furthermore, the non-significant tendency of overachievement on the intercept in the case of the zero threshold increased substantially in the case of the $|5|$-threshold, with 0.8 scale points lower income satisfaction for those who exceeded their aspirations by at least 5 ISEI score points. This indicates that the effect on income satisfaction became stronger when AAG values deviated more (by at least 5 ISEI score points) from zero (i.e., became larger). Overall, the influence of the AAG on SWB was strongest for income satisfaction, followed by job satisfaction, and was weakest for general life satisfaction.

Only job satisfaction showed, at threshold $|5|$, a marginally significant positive effect of overachievement on the linear slope (i.e., mean growth rate of change), indicating that surpassing occupational aspirations by at least 5 ISEI score points led to a 0.4 scale points higher increase in job satisfaction over time. Thus, Hypotheses $2 \mathrm{a}$ and $2 \mathrm{~b}$ could not be confirmed, as the AAG did not predict the development of SWB over time.

The intercept-slope covariance again showed the strongest negative effect for income satisfaction, but this effect was slightly decreased compared to Model I. Higher initial levels of SWB were related to 1.1 scale points steeper declines in income satisfaction over time. 


\section{The AAG and the Covariates Predicting SWB (Model III)}

The third model we analyzed was the conditional LGC model with the two dummy AAGs and all control variables as predictors (Model III). The model results are displayed in Appendix H in the Supplementary Online Material. The regression coefficients of under- and overachievement on the intercept and the linear slope of SWB are additionally depicted in Figure 2. When additionally taking the covariates into account, the picture was similar to that in Model II in terms of the directions and strength of the effects, thus confirming Hypothesis 1a that underachievement (and also overachievement) predicts lower initial levels of SWB after VET entry. Again, the impact of the AAG on income satisfaction was strongest, followed by job satisfaction, and the impact of the AAG on general life satisfaction was weakest.

Taking a look at the three SWB domains separately revealed, first, that the negative effects of under- and overachievement on the initial level of general life satisfaction decreased slightly compared to Modell II, and that there was a significant influence of overachievement only on the intercept at threshold 0 . However, the effect at threshold $|5|$ was still recognizable and was comparable to that in Model II. Surpassing occupational aspirations led to 0.4 scale points lower general life satisfaction. Second, the negative effects of under- and overachievement on the initial level of job satisfaction were very similar to those in Model II, and increased only very slightly compared to that model. Falling short of or surpassing occupational aspirations led to $0.4-0.7$ scale points lower job satisfaction. Third, the negative effects of under- and overachievement on the initial level of income satisfaction even increased substantially — especially at threshold $|5|$ - thereby revealing that falling short of or exceeding aspirations by at least 5 ISEI score points (i.e., a large AAG) was related to almost 1 scale point lower income satisfaction. Hypothesis $1 \mathrm{~b}$ could be confirmed especially in the case of income satisfaction and job satisfaction, as large AAGs were associated with lower initial levels of SWB. 


\section{Figure 2}

Three Domains of SWB Regressed on the AAG (Model III) - to as Intercept and t 2 as Intercept

A

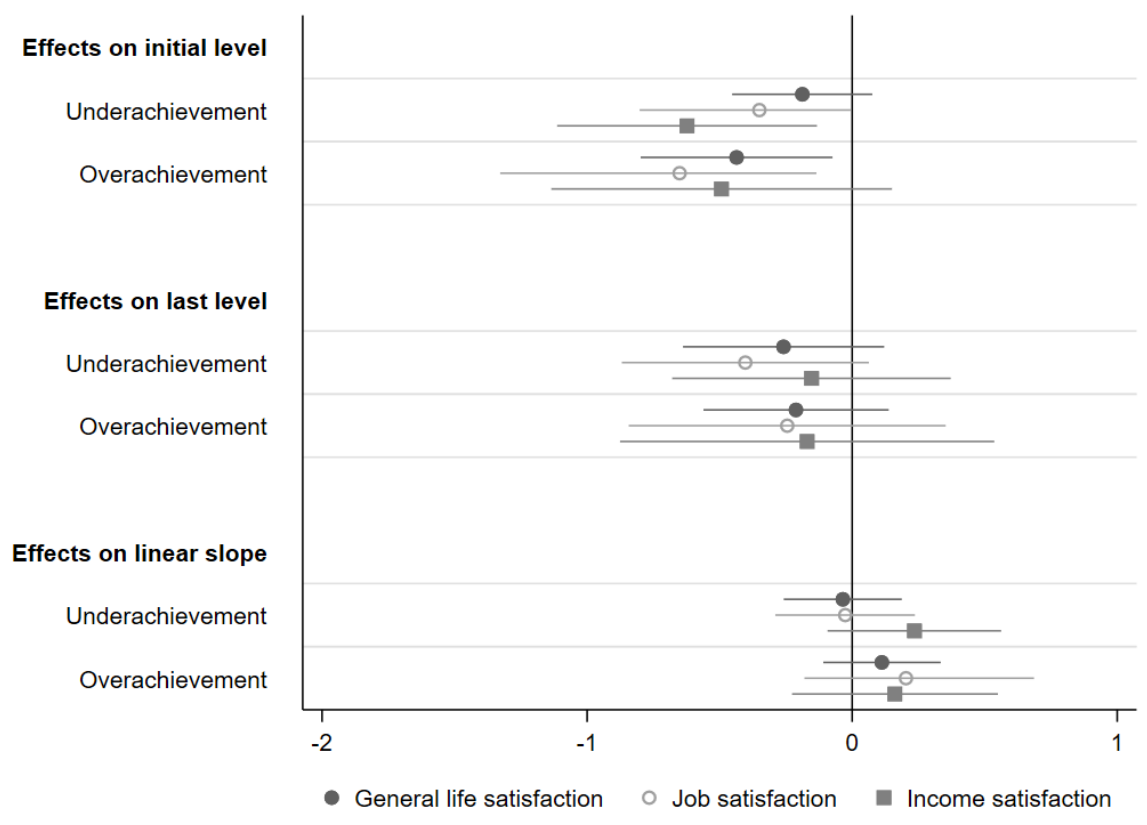

B

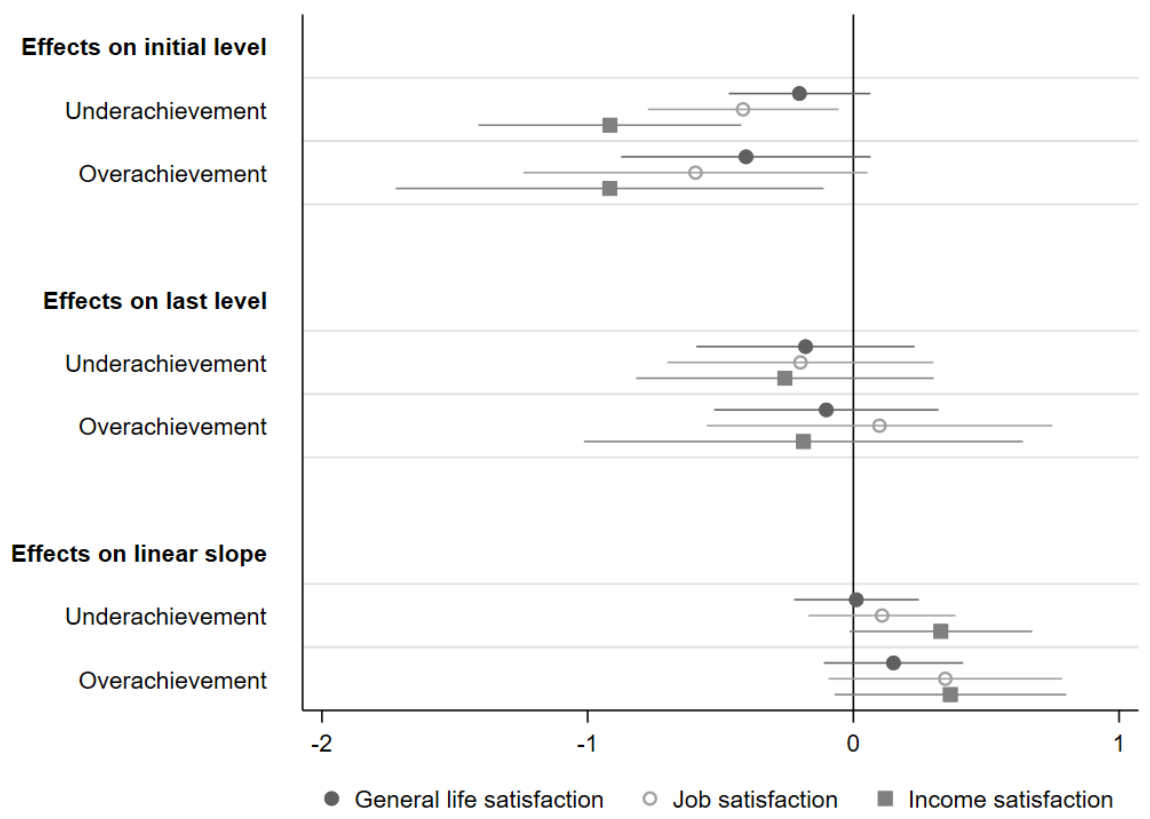

Note. Unstandardized regression coefficients with $95 \%$ confidence interval. $N=1,536$.

A: AAG-threshold 0. B: AAG-threshold |5|. 
Similar to Model II, there was no significant impact of the AAG on the mean rate of change in SWB for any of the three SWB domains. However, there were nevertheless small positive tendencies that even increased at threshold $|5|$ : Exceeding aspirations was related to $0.2-0.4$ scale points higher increases in SWB over time, and falling short of aspirations was related to up to 0.3 scale points higher increases in SWB over time (lowest for general life satisfaction and highest for income satisfaction). Thus, Hypotheses $2 \mathrm{a}$ and $2 \mathrm{~b}$ could not be confirmed, as SWB increased only slightly over the course of VET as a function of the AAG (and of large AAGs).

The intercept-slope covariance was significant for income satisfaction (threshold 0 and $|5|$ ) and for job satisfaction (threshold 0 only but there was also a tendency for threshold $|5|$ in the same - namely negative-direction). In contrast to Models I and II, the linear slope was positive in both SWB domains (but for job satisfaction at threshold $|5|$ ), implying that higher initial levels of SWB were related to $0.6-1.1$ scale points lower increase, or slower rates of positive change, in SWB over time, and lower initial levels of SWB were related to steeper increases or a steeper positive slope.

\section{Prediction of the Last Level of SWB}

Second, we predicted the level of general life satisfaction, job satisfaction, and income satisfaction reached at the last observation at $t_{2}$ to investigate whether experiencing an AAG predicted the level of SWB in the final phase of VET, and whether there were differences compared to the models where the initial level of SWB (i.e., $\mathrm{t}_{0}$ ) was defined as the intercept. In the following, we describe only the most important results that differ compared to the models with the intercept defined as $\mathrm{t}_{0}$, and only for Model III including the covariates. The model coefficients that differ compared to the model predicting the initial level of SWB are displayed in Table 2 (for Model I), in Appendix G (for Model II), and in Appendix H (for Model III). The regression coefficients of under- and overachievement on the intercept of SWB (Model III) are additionally depicted in Figure 2. 
In almost all cases, the effects of under- and overachievement on SWB were discernibly lower than for the models where the initial level was the intercept. However, with one exception, the direction of the effects remained the same ( 0.1 to -0.4 scale points vs. -0.2 to -0.9 scale points). Thus, apprentices who experienced an AAG were no longer less satisfied than their peers who had obtained the VET positions in the occupations to which they aspired, although a slight tendency toward lower SWB was still apparent.

\section{Discussion}

The present study examined the consequences of an occupational AAG (i.e., the discrepancy between the SES of the aspired and attained occupation) for three SWB domains (general life satisfaction, job satisfaction, and income satisfaction) among apprentices in Germany. We analyzed the relevance of underachievement and overachievement compared to no AAG on the initial and final level of SWB after VET entry as well as on the development of SWB over the course of VET for a period of up to 2 years.

\section{Experiencing an AAG Decreases Apprentices' Initial and Final Levels of SWB}

Our preregistered Hypotheses $1 \mathrm{a}$ and $1 \mathrm{~b}$ relating to the initial levels of SWB, which were based on aspiration theory (Starbuck, 1963), multiple discrepancy theory (Michalos, 1985), and self-discrepancy theory (Higgins, 1987), could be fully confirmed. Consistent with evidence from the literature (e.g., Carr, 1997; Hardie, 2014), unmet expectations (underachievement and overachievement) were associated with lower initial levels of SWB during the first year of VET. The strongest negative effects of an AAG on SWB were found for income satisfaction, followed by job satisfaction - that is, work-related SWB - particularly for large negative AAGs. For general life satisfaction, we found only small effects.

It may be surprising at first glance that we also observed a clear negative impact of overachievement on all three SWB domains. This finding contradicts the level of aspiration theory (e.g., Starbuck, 1963), according to which realized or exceeded aspirations are perceived as success and therefore enhance SWB. A possible explanation for this is that the SES 
of the VET position attained is not decisive for apprentices' SWB; rather, the decisive factor is whether or not apprentices obtain the exact occupation (i.e., VET position) to which they aspired, regardless of whether the position they attained confers a higher (or lower) social status than the occupation to which they originally aspired. A study with an adult female sample reported similar results_-namely, that both under- and overachievement were related to lower perceptions of being very successful in work life (Carr, 1997). This raises the question of what actually determines whether an AAG will negatively impact SWB. Speculatively, the decisive factors could be the occupational fields in question (see also Wicht et al., 2021) and the skills and characteristics required for the occupations aspired to and attained. This assumption is in line with previous findings showing that AAGs with respect to the occupational field are most relevant for both enjoyment of and dropout from VET (Ahrens et al., 2021a; Beckmann et al., 2021).

Moreover, the results indicate that overachievement has an even stronger negative effect on job satisfaction and general life satisfaction than underachievement does, and that at threshold $|5|$ overachievement and underachievement have an equally strong and more pronounced effect on income satisfaction. Thus, our results, do not support the assumption that underachievement is more relevant for SWB than overachievement. One possible reason for this finding is that overachievers might perceive the tasks associated with their VET positions to be too challenging and demanding, which is reflected in their job satisfaction and general life satisfaction. The same applies to income satisfaction. Income may not be evaluated in absolute terms but rather against the background of the individual's own effort.

Because both under- and overachievement showed similar patterns, and because not achieving the desired VET position — rather than the status difference between the occupation aspired to and the occupation in which a VET position was attained — appeared to be crucial, we ran Model III including the confounding variables again (intercept defined as initial level of SWB only), combining the groups of under- and overachievers and testing them against 
those with a perfect match. As expected, the effect sizes lay roughly in the middle between the effects of under- and overachievement, and were all negative (general life satisfaction: -0.3 , job satisfaction: -0.5 , income satisfaction: -0.6 to -0.9 scale points; see Appendix $\mathrm{H}$ in the Supplementary Online Material). However, the effects of the combined group were more often statistically significant - inter alia, the impact of the AAG on the change in income satisfaction was also significant ( -0.3 scale points $)$ - presumably because the sample sizes were larger. These results reinforce the interpretation that neither the direction of the AAG nor the extent of the AAG in terms of SES is the key determinant of whether it will negatively impact SWB, but rather the mere fact of whether or not apprentices are able to obtain the exact type of position to which they aspired.

\section{Experiencing an AAG Is Largely Unrelated to the Development of SWB Over the}

\section{Course of VET}

Our results did not confirm our preregistered Hypotheses $2 \mathrm{a}$ and $2 \mathrm{~b}$ relating to changes in SWB over time, which were based on the concept of the hedonic treadmill (Brickman \& Campbell, 1971). Although there was a consistent tendency across outcomes for the initially lower SWB levels of individuals who experienced an AAG to gradually return to the levels of their peers who did not experience an AAG, few of the associations between the AAG and the slope of SWB were statistically significant. This is in line with the observation that SWB often returns to a stable baseline level after positive or negative life experiences such as filial bereavement or unemployment (e.g., Leopold \& Lechner, 2015; Luhmann et al., 2012), a phenomenon also known as a process of hedonic adaptation

Although the effect sizes were rather small for the association between AAG and SWB development, in most cases there were somewhat higher tendencies toward dissatisfaction in the case of large AAGs and of overachievement. In all, however, both overachievers and underachievers were more dissatisfied at the beginning of VET, as reflected in the clear and significant differences (compared with those who experienced a perfect match between 
aspirations and attainment). At the end of VET, those with an AAG remained slightly more dissatisfied, but these differences were no longer significant and decreased substantially, as indicated by the smaller effect sizes of the AAG at the last SWB level compared with the initial level. In this context, it should however be noted that the remaining sample size for the last observation had decreased considerably. This finding also corresponds to our above interpretation that not realizing occupational aspirations has negative consequences on SWB, regardless of the SES of the occupations in question, and that this is related to occupational field, interests, and skills.

\section{Implications}

To sum up, the present investigation reveals that both negative and positive occupational AAGs (i.e., under- and overachievement) impair the level of SWB after entry into VET and - to a lesser degree - in the final phase of VET, and predict a tendency toward a larger positive change in SWB over the course of VET. By looking at three different domains of SWB, we were able to provide a nuanced picture of the consequences for SWB of an occupational AAG among adolescents in an early-career stage over a period of 2 years in Germany. This constitutes a substantial contribution to the literature on educational transitions. Because the AAG is a highly prevalent phenomenon (e.g., Nießen et al., 2021) that affects SWB, which in turn is a predictor of various work-related outcomes such as work motivation (e.g., Ton \& Hansen, 2001) and later undesired job turnover (e.g., Medici et al., 2020), and because VET determines career options within a specific occupational field, it is likely that SWB serves as a mediator between the AAG and long-term consequences for career progression. Hence, to better understand this phenomenon, it is a task of future research to scrutinize this mediating role of the AAG, for example, in dropout from VET (see, e.g., Beckmann et al., 2021), completion of VET, and other "harder" career outcomes. The findings of this research will be relevant for policymakers and employers who wish to initiate interventions to improve SWB during VET to support further career development - especially because the wishes and 
expectations of school leavers do not necessarily coincide with the VET positions available on the labor market (i.e., employment realities; Hoff et al., 2021).

\section{Limitations of the Present Study and Directions for Future Research}

The present study has some limitations. First, the focus was on the level and development of SWB after the transition from school to VET and during VET, and for this purpose we used data from school leavers whose school-leaving qualifications ranged from the basic school-leaving qualification (Hauptschulabschluss) to the general higher education entrance qualification (Abitur). As the latter qualification entitles school leavers to attend university, future research is needed to ascertain whether our findings can be generalized to other educational transitions and replicated in other national contexts.

Furthermore, our results suggest that the AAG no longer has a (large) impact on the level of SWB at the end of VET or on the development of SWB during VET. However, the statistical power of our analyses was somewhat limited by missing data arising inter alia from panel attrition. These missing data also meant that we were unable to observe the development of SWB during VET over a longer (ideally 3-year) period as originally intended. Thus, future research should explore this tendency further over a longer period. Indeed, the literature emphasizes that underachievers often downgrade their aspirations over time to better cope with the disappointments they experience (e.g., Tomasik et al., 2009). Whether this is also the case for overachievers in the opposite way remains to be clarified.

\section{Conclusion}

The results of the present study reveal differences in apprentices' level of SWB (most notably for work-related satisfaction) as a function of an occupational AAG at the beginning of VET: Those who did not obtain a VET position in their aspired occupation were more dissatisfied at the beginning of VET than those who did. At the end of VET, there were no longer any significant differences between the two groups, but a slight tendency in the same 
direction was observable. Particularly strong discrepancies between aspirations and attainment led to higher dissatisfaction. However, it was not a particular type of AAG (overachievement vs. underachievement) that appeared to impair SWB, but rather the fact that a VET position in the aspired occupation was not obtained, regardless of the SES that that position conferred. Related to this finding, we found no clear evidence of different changes in SWB between individuals with and without an AAG, but again there was a slight tendency for an increase in SWB over the course of VET for those with an AAG. Thus, our results show that experiencing an $\mathrm{AAG}$ - whether overachievement or underachievement - is detrimental to SWB, and tends to remain so (although with waning effect sizes) over a period of 2 years. Further research should extend these findings by examining both the impact of an occupational AAG and the mediating role of SWB on subsequent career development. 


\section{References}

Ahrens, L., Fischer, M., Kleinert, C., \& Schels, B. (2021a). Compromises in occupational choice and stability of vocational education and training. In C. Nägele, B. E. Stalder, \& M. Weich (Eds.), Pathways in vocational education and training and lifelong learning. Proceedings of the 4th Crossing Boundaries Conference in Vocational Education and Training, Muttenz and Bern online, 8.-9. April (pp. 24-31). European Research Network on Vocational Education and Training, VETNET, University of Applied Sciences and Arts Northwestern Switzerland and Bern University of Teacher Education. https://doi.org/10.5281/zenodo.4603059

Ahrens, L., Fischer, M., Schels, B., \& Kleinert, C. (2021b). Nicht alle Wünsche werden wahr: Welche Kompromisse Jugendliche beim Ausbildungsberuf eingehen [Not all wishes come true: What compromises young people make when it comes to apprenticeships]. IAB-Forum. https://www.iab-forum.de/nicht-alle-wuensche-werden-wahr-welchekompromisse-jugendliche-beim-ausbildungsberuf-eingehen/

Aiken, L. R., \& Groth-Marnat, G. (2006). Psychological testing and assessment (12th ed.). Pearson.

Beckmann, J., Wicht, A., \& Siembab, M. (2021). Career compromises and dropout from vocational education and training in Germany. SocArXiv. https://doi.org/10.31235/osf.io/4ztv9

Brickman, P., \& Campbell, D. T. (1971). Hedonic relativism and planning the good society. In M. H. Appley (Ed.), Adaptation-level theory (pp. 287-305). Academic Press.

Carr, D. (1997). The fulfillment of career dreams at midlife: Does it matter for women's mental health? Journal of Health and Social Behavior, 38(4), 331-344. https://doi.org/10.2307/2955429 
Diener, E., Lucas, R. E., \& Scollon, C. N. (2006). Beyond the hedonic treadmill: Revising the adaptation theory of well-being. The American Psychologist, 61(4), 305-314. https://doi.org/10.1037/0003-066X.61.4.305

Ganzeboom, H. B. G., De Graaf, P. M., \& Treiman, D. J. (1992). A standard international socio-economic index of occupational status. Social Science Research, 21, 1-56. https://doi.org/10.1016/0049-089X(92)90017-B

Ganzeboom, H. B. G., \& Treiman, D. J. (2003). Three internationally standardised measures for comparative research on occupational status. In J. H. P. Hoffmeyer-Zlotnik \& C. Wolf (Eds.), Advances in cross-national comparison. A European working book for demographic and socio-economic variables (pp. 159-193). Kluwer Academic/Plenum Publishers.

Giver, H., Faber, A., Hannerz, H., Strøyer, J., \& Rugulies, R. (2010). Psychological well-being as a predictor of dropout among recently qualified Danish eldercare workers. Scandinavian Journal of Public Health, 38(3), 239-245.

https://doi.org/10.1177/1403494809348939

Goebel, J., Grabka, M. M., Liebig, S., Kroh, M., Richter, D., Schröder, C., \& Schupp, J. (2019). The German Socio-Economic Panel (SOEP). Jahrbücher für Nationalökonomie und Statistik, 239(2), 345-360. https://doi.org/10.1515/jbnst-20180022

Haase, C. M., Poulin, M. J., \& Heckhausen, J. (2012). Happiness as a motivator: Positive affect predicts primary control striving for career and educational goals. Personality and Social Psychology Bulletin, 38(8), 1093-1104. https://doi.org/10.1177/0146167212444906

Hardie, J. H. (2014). The consequences of unrealized occupational goals in the transition to adulthood. Social Science Research, 48, 196-211. https://doi.org/10.1016/j.ssresearch.2014.06.006 
Heckhausen, J., \& Tomasik, M. J. (2002). Get an apprenticeship before school is out: How German adolescents adjust vocational aspirations when getting close to a developmental deadline. Journal of Vocational Behavior, 60(2), 199-219. https://doi.org/10.1006/jvbe.2001.1864

Higgins, E. T. (1987). Self-discrepancy: A theory relating self and affect. Psychological Review, 94(3), 319-340. https://doi.org/10.1037/0033-295X.94.3.319

Hoff, K., Van Egdom, D., Napolitano, C., Hanna, A., \& Rounds, J. (2021). Dream jobs and employment realities: How adolescents' career aspirations compare to labor demands and automation risks. Journal of Career Assessment. Advance online publication. https://doi.org/10.1177/10690727211026183

Hu, L., \& Bentler, P. M. (1999). Cutoff criteria for fit indexes in covariance structure analysis: Conventional criteria versus new alternatives. Structural Equation Modeling, 6(1), 155. https://doi.org/10.1080/10705519909540118

International Labour Office. (1990). International standard classification of occupations: ISCO-88. International Labour Office.

Kahneman, D., \& Tversky, A. (1979). Prospect theory: An analysis of decision under risk. Econometrica, 47(2), 263-291.

Kleinert, C., \& Schels, B. (2020). Zurück zur Norm? Kompromissbildung zwischen geschlechtstypischen und -untypischen Berufsaspirationen, Bewerbungs- und Ausbildungsberufen [Back to the norm? Compromises between gender-typical and -atypical occupational aspirations, applications, and vocational training occupations]. Kölner Zeitschrift für Soziologie, 72, 229-260. https://doi.org/10.1007/s11577-020-00668-1

Leopold, T., \& Lechner, C. M. (2015). Parents' death and adult well-being: Gender, age, and adaptation to filial bereavement. Journal of Marriage and Family, 77(3), 747-760. https://doi.org/10.1111/jomf.12186 
Luhmann, M., \& Hennecke, M. (2017). The motivational consequences of life satisfaction. Motivation Science, 3(1), 51-75. https://doi.org/10.1037/mot0000048

Luhmann, M., Hofmann, W., Eid, M., \& Lucas, R. E. (2012). Subjective well-being and adaptation to life events: A meta-analysis. Journal of Personality and Social Psychology, 102(3), 592-615. https://doi.org/10.1037/a0025948

Medici G., Tschopp, C., Grote, G., \& Hirschi, A. (2020). Grass roots of occupational change: Understanding mobility in vocational careers. Journal of Vocational Behavior, 122, 103480. https://doi.org/10.1016/j.jvb.2020.103480

Michalos, A. C. (1985). Multiple discrepancies theory (MDT). Social Indicators Research, 16, 347-413. https://doi.org/10.1007/BF00333288

Muthén, L. K., \& Muthén, B. O. (1998-2017). Mplus user's guide (8th ed). Muthén \& Muthén. https://www.statmodel.com/download/usersguide/MplusUserGuideVer_8.pdf

Nießen, D., Wicht, A., Schoon, I., \& Lechner, C. M. (2021). “You can't always get what you want": Prevalence and predictors of the aspiration-attainment gap after the school-towork transition. PsyArXiv. https://doi.org/10.31234/osf.io/fkpgw

Paat, Y.-F. (2016). Strain, psychological conflicts, aspirations-attainment gap, and depressive tendencies among youth of Mexican immigrants. Social Work in Public Health, 31(1), 19-29. https://doi.org/10.1080/19371918.2015.1087910

Protsch, P., \& Solga, H. (2016). The social stratification of the German VET system. Journal of Education and Work, 29(6), 637-661. https://doi.org/10.1080/13639080.2015.1024643

Reynolds, J. R., \& Baird, C. L. (2010). Is there a downside to shooting for the stars? Unrealized educational expectations and symptoms of depression. American Sociological Review, 75(1), 151-172. https://doi.org/10.1177/0003122409357064 
Rode, J. C. (2004). Job satisfaction and life satisfaction revisited: A longitudinal test of an integrated model. Human Relations, 57(9), 1205-1230. https://doi.org/10.1177/0018726704047143

Rojas, M. (2007). The complexity of wellbeing: A life-satisfaction conception and a domainsof-life approach. In I. Gough \& J. McGregor (Eds.), Wellbeing in developing countries: From theory to research (pp. 259-280). Cambridge University Press. https://doi.org/10.1017/CBO9780511488986.013

Ruggeri, K., Garcia-Garzon, E., Maguire, Á., Matz, S., \& Huppert, F. A. (2020). Well-being is more than happiness and life satisfaction: A multidimensional analysis of 21 countries. Health and Quality of Life Outcomes, 18, Article 192. https://doi.org/10.1186/s12955020-01423-y

Schneider, S. (2008). Applying the ISCED-97 to the German educational qualifications. In S. L. Schneider (Ed.), The International Standard Classification of Education (ISCED97): An evaluation of content and criterion validity for 15 European countries (pp. 76102). MZES.

Schupp, J., \& Gerlitz, J.-Y. (2014). Big Five Inventory-SOEP (BFI-S). Zusammenstellung sozialwissenschaftlicher Items und Skalen (ZIS). https://doi.org/10.6102/zis54

Siembab, M., \& Stawarz, N. (2019). How does life satisfaction change during the transition from school to work? A study of ninth and tenth-grade school-leavers in Germany. Journal of Happiness Studies, 20, 165-183. https://doi.org/10.1007/s10902-017-9945-z

Smith, P., \& Frank, J. (2005). When aspirations and achievements don't meet. A longitudinal examination of the differential effect of education and occupational attainment on declines in self-rated health among Canadian labour force participants. International Journal of Epidemiology, 34(4), 827-834. https://doi.org/10.1093/ije/dyi047

SOEP Group (2020a). SOEP-Core - 2018: Individual (PAPI, with references to variables). SOEP Survey Papers 816: Series A - Survey Instruments (Erhebungsinstrumente). 
DIW Berlin/SOEP. https://www.diw.de/de/diw_01.c.741445.de/publikationen/soepsurveypapers/2020_0816/soep-core___2018_individual_papi_with_reference_to_variables.html

SOEP Group (2020b). SOEP-Core - 2018: Youth (16-17-year-olds, PAPI, with reference to variables). SOEP Survey Papers 807: Series A - Survey Instruments (Erhebungsinstrumente). DIW Berlin/SOEP. https://www.diw.de/de/diw_01.c.785098.de/s_11829.html

Starbuck, W. H. (1963). Level of aspiration theory and economic behavior. Behavioral Science, 8(2), 128-136. https://doi.org/10.1002/bs.3830080205

Sweet, J. J., Nelson, N. W., \& Moberg, P. J. (2006). The TCN/AACN 2005 "Salary Survey”: Professional practices, beliefs, and incomes of U.S. neuropsychologists. The Clinical Neuropsychologist, 20(3), 325-364. https://doi.org/10.1080/13854040600760488

Tomasik, M. J., Hardy, S., Haase, C. M., \& Heckhausen, J. (2009). Adaptive adjustment of vocational aspirations among German youths during the transition from school to work. Journal of Vocational Behavior, 74, 38-46. https://doi.org/10.1016/j.jvb.2008.10.003

Ton, M.-T. N., \& Hansen, J.-I. C. (2001). Using a person-environment fit framework to predict satisfaction and motivation in work and marital roles. Journal of Career Assessment, 9(4), 315-331. https://doi.org/10.1177/106907270100900401

Treiman, D. J. (1977). Occupational prestige in comparative perspective. Academic Press.

Wicht, A., Miyamoto, A., \& Lechner, C. M. (2021). Are girls more ambitious than boys? Vocational interests partly explain gender differences in occupational aspirations. Journal of Career Development. Advance online publication. https://doi.org/10.1177/0894845321991665

Zagórski, K. (2011). Income and happiness in time of post-communist modernization. Social Indicators Research, 104(2), 331-349. https://doi.org/10.1007/s11205-010-9749-6

Züll, C. (2016). The coding of occupations (Version 2.0). GESIS Survey Guidelines. GESIS Leibniz Institute for the Social Sciences. https://doi.org/10.15465/gesis-sg_en_019 


\section{Appendix A}

\section{The Consequences of Aspiration-Attainment Gaps for Subjective Well-Being: Previous Evidence on Possible Confounding Variables}

A recent study of adolescents beginning vocational education and training (VET) in Germany reported that lower levels of Big Five Emotional Stability, Agreeableness, and Conscientiousness, and higher levels of Big Five Openness were associated with a higher likelihood of experiencing an occupational aspiration-attainment gap (AAG)/a higher risk of a larger AAG (Nießen et al., 2021). Moreover, across different studies, the Big Five dimensions have consistently been found to be positively related to domains of subjective well-being (SWB) — for example, satisfaction with VET (e.g., Nießen et al., 2020), job satisfaction (for a review, see Therasa \& Vijayabanu, 2015), and life satisfaction (e.g., Bond et al., 2020)—although not all dimensions were always equally relevant. Individuals with lower parental SES have been found to be more likely to experience an educational (e.g., Hanson, 1994) or occupational (e.g., Nießen et al., 2021) AAG, whereas higher parental SES has been found to be associated with a larger AAG (e.g., Nießen et al., 2021) and higher life satisfaction (e.g., Chen et al., 2016). Having a migration background has been shown to be related to a higher likelihood of experiencing an occupational AAG and a larger occupational AAG (e.g., Nießen et al., 2021). Furthermore, studies have reported that, compared to Whites, Blacks (and Hispanics) tend to report lower job satisfaction (e.g., Ganzach, 1998) and life satisfaction (e.g., Barger et al., 2009).

Previous findings regarding the relationship between gender, the AAG, and SWB have been inconsistent. Most studies have shown that males have a higher likelihood of experiencing an educational (e.g., Hanson, 1994) or occupational (e.g., Nießen et al., 2021) AAG, and that females are more likely to experience larger educational (e.g., Paat, 2015) or occupational (e.g., Nießen et al., 2021) AAGs. With respect to SWB, a recent cross-nationally comparative study found higher life satisfaction in females in 18 nations (Bond et al., 2020). Other studies 
have reported, for example, higher VET satisfaction in males (e.g., Nießen et al., 2020) or higher job satisfaction in females (e.g., Bui, 2017).

\section{References}

Barger, S. D., Donoho, C. J., \& Wayment, H. A. (2009). The relative contributions of race/ethnicity, socioeconomic status, health, and social relationships to life satisfaction in the United States. Quality of Life Research, 18(2), 179-189. https://doi.org/10.1007/s11136008-9426-2

Bond, M. H., Lu, Q., Lun, V. M.-C., \& Smith, P. B. (2020). The wealth and competitiveness of national economic systems moderates the importance of Big Five personality dimensions for life satisfaction of employed persons in 18 nations. Journal of Cross-Cultural Psychology, 51(5), 267-282. https://doi.org/10.1177/0022022120924756

Bui, H. T. (2017). Big Five personality traits and job satisfaction: Evidence from a national sample. Journal of General Management, 42(3), 21-30. https://doi.org/10.1177/0306307016687990

Chen, W., Niu, G.-F., Zhang, D.-J., Fan, C.-Y., Tian, Y., \& Zhou, Z.-K. (2016). Socioeconomic status and life satisfaction in Chinese adolescents: Analysis of self-esteem as a mediator and optimism as a moderator. Personality and Individual Differences, 95, 105-109. https://doi.org/10.1016/j.paid.2016.01.036

Ganzach, Y. (1998). Intelligence and job satisfaction. Academy of Management Journal, 41(5), 526-539. https://doi.org/10.2307/256940

Hanson, S. L. (1994). Lost talent: Unrealized educational aspirations and expectations among U.S. youths. Sociology of Education, 67(3), 159-183. https://doi.org/10.2307/2112789

Nießen, D., Danner, S., Spengler, M., \& Lechner, C. M. (2020). Big Five personality traits predict successful transitions from school to vocational education: A large-scale study. Frontiers in Psychology, 11, 1827. http://doi.org/10.3389/fpsyg.2020.01827 
Nießen, D., Wicht, A., Schoon, I., \& Lechner, C. M. (2021). “You can't always get what you want": Prevalence and predictors of the aspiration-attainment gap after the school-towork transition. PsyArXiv. https://doi.org/10.31234/osf.io/fkpgw

Paat, Y.-F. (2015). Children of Mexican immigrants' aspiration-attainment gap and educational resilience. Diaspora, Indigenous, and Minority Education, 9(1), 37-53. https://doi.org/10.1080/15595692.2014.980804

Therasa, C., \& Vijayabanu, C. (2015). The impact of Big Five personality traits and positive psychological strengths towards job satisfaction: A review. Periodica Polytechnica Social and Management Sciences, 23(2), 142-150. https://doi.org/10.3311/PPso.7620 


\section{Appendix B}

Correlations Between Three Domains of Subjective Well-Being and all Other Variables Included in the Study

\begin{tabular}{|c|c|c|c|c|c|c|c|c|c|c|}
\hline & \multicolumn{10}{|c|}{$r[95 \% \mathrm{CI}]$ (pairwise $N$ ) } \\
\hline & \multicolumn{4}{|c|}{ General life satisfaction } & \multicolumn{3}{|c|}{ Job satisfaction } & \multicolumn{3}{|c|}{ Income satisfaction } \\
\hline & $\mathrm{t}_{-1}$ & $\mathrm{t}_{0}$ & $\mathrm{t}_{1}$ & $\mathrm{t}_{2}$ & $\mathrm{t}_{0}$ & $\mathrm{t}_{1}$ & $\mathrm{t}_{2}$ & $\mathrm{t}_{0}$ & $\mathrm{t}_{1}$ & $\mathrm{t}_{2}$ \\
\hline $\begin{array}{l}\text { General life satisfac- } \\
\text { tion } t_{0}\end{array}$ & $\begin{array}{l}.35 \\
{[.29, .41]} \\
(773)\end{array}$ & & & & & & & & & \\
\hline $\begin{array}{l}\text { General life satisfac- } \\
\text { tion } t_{1}\end{array}$ & $\begin{array}{l}.28 \\
{[.21, .36]} \\
(575)\end{array}$ & $\begin{array}{l}.42 \\
{[.36, .48]} \\
(699)\end{array}$ & & & & & & & & \\
\hline $\begin{array}{l}\text { General life satisfac- } \\
\text { tion } t_{2}\end{array}$ & $\begin{array}{l}.29 \\
{[.18, .39]} \\
(307)\end{array}$ & $\begin{array}{l}.34 \\
{[.24, .42]} \\
(364)\end{array}$ & $\begin{array}{l}.49 \\
{[.41, .55]} \\
(429)\end{array}$ & & & & & & & \\
\hline Job satisfaction $t_{0}$ & $\begin{array}{l}.16 \\
{[.09, .23]} \\
(689)\end{array}$ & $\begin{array}{l}.30 \\
{[.23, .37]} \\
(696)\end{array}$ & $\begin{array}{l}.24 \\
{[.15, .33]} \\
(458)\end{array}$ & $\begin{array}{l}.17 \\
{[.05, .30]} \\
(237)\end{array}$ & & & & & & \\
\hline Job satisfaction $t_{1}$ & $\begin{array}{l}.12 \\
{[.04, .20]} \\
(556)\end{array}$ & $\begin{array}{l}.25 \\
{[.18, .32]} \\
(669)\end{array}$ & $\begin{array}{l}.33 \\
{[.26, .39]} \\
(780)\end{array}$ & $\begin{array}{l}.27 \\
{[.18, .36]} \\
(418)\end{array}$ & $\begin{array}{l}.46 \\
{[.39, .53]} \\
(449)\end{array}$ & & & & & \\
\hline Job satisfaction $t_{2}$ & $\begin{array}{l}.11 \\
{[-.01, .22]} \\
(296)\end{array}$ & $\begin{array}{l}.31 \\
{[.21, .40]} \\
(350)\end{array}$ & $\begin{array}{l}.21 \\
{[.11, .30]} \\
(415)\end{array}$ & $\begin{array}{l}.39 \\
{[.30, .47]} \\
(420)\end{array}$ & $\begin{array}{l}.37 \\
{[.26, .48]} \\
(228) \\
\end{array}$ & $\begin{array}{l}.49 \\
{[.41, .56]} \\
(407)\end{array}$ & & & & \\
\hline Income satisfaction $t_{0}$ & $\begin{array}{l}.23 \\
{[.16, .30]} \\
(756)\end{array}$ & $\begin{array}{l}.30 \\
{[.24, .36]} \\
(764)\end{array}$ & $\begin{array}{l}.24 \\
{[.15, .32]} \\
(488)\end{array}$ & $\begin{array}{l}.06 \\
{[-.06, .18]} \\
(255)\end{array}$ & $\begin{array}{l}.36 \\
{[.29, .42]} \\
(697)\end{array}$ & $\begin{array}{l}.14 \\
{[.06, .23]} \\
(470)\end{array}$ & $\begin{array}{l}.07 \\
{[-.05, .20]} \\
(245)\end{array}$ & & & \\
\hline Income satisfaction $t_{1}$ & $\begin{array}{l}.17 \\
{[.09, .24]} \\
(570)\end{array}$ & $\begin{array}{l}.18 \\
{[.10, .25]} \\
(688)\end{array}$ & $\begin{array}{l}.33 \\
{[.27, .39]} \\
(803)\end{array}$ & $\begin{array}{l}.18 \\
{[.09, .27]} \\
(425)\end{array}$ & $\begin{array}{l}.22 \\
{[.13, .30]} \\
(453)\end{array}$ & $\begin{array}{l}.33 \\
{[.27, .39]} \\
(781)\end{array}$ & $\begin{array}{l}.12 \\
{[.02, .21]} \\
(411)\end{array}$ & $\begin{array}{l}.57 \\
{[.51, .63]} \\
(483)\end{array}$ & & \\
\hline Income satisfaction $t_{2}$ & $\begin{array}{l}.17 \\
{[.06, .28]} \\
(306)\end{array}$ & $\begin{array}{l}.23 \\
{[.13, .32]} \\
(361)\end{array}$ & $\begin{array}{l}.25 \\
{[.16, .34]} \\
(427)\end{array}$ & $\begin{array}{l}.28 \\
{[.18, .36]} \\
(432)\end{array}$ & $\begin{array}{l}.17 \\
{[.04, .29]} \\
(235)\end{array}$ & $\begin{array}{l}.30 \\
{[.22, .39]} \\
(416)\end{array}$ & $\begin{array}{l}.28 \\
{[.19, .37]} \\
(422)\end{array}$ & $\begin{array}{l}.45 \\
{[.35, .55]} \\
(253)\end{array}$ & $\begin{array}{l}.59 \\
{[.52, .65]} \\
(422)\end{array}$ & \\
\hline
\end{tabular}

(continued) 


\begin{tabular}{|c|c|c|c|c|c|c|c|c|c|c|}
\hline & \multicolumn{10}{|c|}{$r[95 \% \mathrm{CI}]($ pairwise $N)$} \\
\hline & \multicolumn{4}{|c|}{ General life satisfaction } & \multicolumn{3}{|c|}{ Job satisfaction } & \multicolumn{3}{|c|}{ Income satisfaction } \\
\hline & $\mathrm{t}_{-1}$ & $\mathrm{t}_{0}$ & $\mathrm{t}_{1}$ & $\mathrm{t}_{2}$ & $\mathrm{t}_{0}$ & $\mathrm{t}_{1}$ & $\mathrm{t}_{2}$ & $\mathrm{t}_{0}$ & $\mathrm{t}_{1}$ & $\mathrm{t}_{2}$ \\
\hline Aspirations & $\begin{array}{l}.00 \\
{[-.06, .07]} \\
(895)\end{array}$ & $\begin{array}{l}-. .01 \\
{[-.08, .06]} \\
(858)\end{array}$ & $\begin{array}{l}-.01 \\
{[-.09, .07]} \\
(615)\end{array}$ & $\begin{array}{l}.01 \\
{[-.10, .12]} \\
(328)\end{array}$ & $\begin{array}{l}-.01 \\
{[-.10, .08]} \\
(502)\end{array}$ & $\begin{array}{l}-.04 \\
{[-.13, .04]} \\
(586)\end{array}$ & $\begin{array}{l}.02 \\
{[-.09, .14]} \\
(315)\end{array}$ & $\begin{array}{l}.04 \\
{[-.04, .13]} \\
(558)\end{array}$ & $\begin{array}{l}.06 \\
{[-.02, .14]} \\
(606)\end{array}$ & $\begin{array}{l}.01 \\
{[-.09, .12]} \\
(325)\end{array}$ \\
\hline Attainment & $\begin{array}{l}-.00 \\
{[-.07, .07]} \\
(783)\end{array}$ & $\begin{array}{l}-.02 \\
{[-.09, .05]} \\
(880)\end{array}$ & $\begin{array}{l}.06 \\
{[-.01, .13]} \\
(759)\end{array}$ & $\begin{array}{l}.08 \\
{[-.02, .17]} \\
(425)\end{array}$ & $\begin{array}{l}-.02 \\
{[-.09, .06]} \\
(659)\end{array}$ & $\begin{array}{l}-.01 \\
{[-.08, .06]} \\
(741)\end{array}$ & $\begin{array}{l}.04 \\
{[-.06, .14]} \\
(416)\end{array}$ & $\begin{array}{l}.09 \\
{[.02, .16]} \\
(699)\end{array}$ & $\begin{array}{l}.09 \\
{[.02, .16]} \\
(753)\end{array}$ & $\begin{array}{l}.09 \\
{[-.01, .18]} \\
(425)\end{array}$ \\
\hline $\begin{array}{l}\text { Aspiration- } \\
\text { attainment gap }\end{array}$ & $\begin{array}{l}.02 \\
{[-.07, .10]} \\
(537)\end{array}$ & $\begin{array}{l}.01 \\
{[-.07, .08]} \\
(649)\end{array}$ & $\begin{array}{l}.02 \\
{[-.06, .10]} \\
(559)\end{array}$ & $\begin{array}{l}.01 \\
{[-.10, .12]} \\
(316)\end{array}$ & $\begin{array}{l}.02 \\
{[-.08, .11]} \\
(458)\end{array}$ & $\begin{array}{l}.04 \\
{[-.05, .12]} \\
(543)\end{array}$ & $\begin{array}{l}.02 \\
{[-.09, .13]} \\
(308)\end{array}$ & $\begin{array}{l}.09 \\
{[.00, .18]} \\
(485)\end{array}$ & $\begin{array}{l}.04 \\
{[-.05, .12]} \\
(552)\end{array}$ & $\begin{array}{l}.07 \\
{[-.05, .17]} \\
(315)\end{array}$ \\
\hline $\begin{array}{l}\text { Underachievement } \\
\text { (threshold 0) }\end{array}$ & $\begin{array}{l}-.06 \\
{[-.14, .03]} \\
(537)\end{array}$ & $\begin{array}{l}-.04 \\
{[-.11, .04]} \\
(649)\end{array}$ & $\begin{array}{l}-.07 \\
{[-.15, .02]} \\
(559)\end{array}$ & $\begin{array}{l}-.05 \\
{[-.16, .06]} \\
(316)\end{array}$ & $\begin{array}{l}-.05 \\
{[-.14, .05]} \\
(458)\end{array}$ & $\begin{array}{l}-.12 \\
{[-.20,-.03]} \\
(543)\end{array}$ & $\begin{array}{l}-.06 \\
{[-.17, .06]} \\
(308)\end{array}$ & $\begin{array}{l}-.11 \\
{[-.20,-.02]} \\
(485)\end{array}$ & $\begin{array}{l}-.10 \\
{[-.18,-.02]} \\
(552)\end{array}$ & $\begin{array}{l}-.09 \\
{[-.20, .02]} \\
(315)\end{array}$ \\
\hline $\begin{array}{l}\text { Overachievement } \\
\text { (threshold 0) }\end{array}$ & $\begin{array}{l}-.10 \\
{[-.18,-.02]} \\
(537)\end{array}$ & $\begin{array}{l}-.07 \\
{[-.15, .00]} \\
(649)\end{array}$ & $\begin{array}{l}-.06 \\
{[-.14, .03]} \\
(559)\end{array}$ & $\begin{array}{l}.04 \\
{[-.07, .15]} \\
(316)\end{array}$ & $\begin{array}{l}-.12 \\
{[.21,-.03]} \\
(458)\end{array}$ & $\begin{array}{l}-.01 \\
{[-.09, .08]} \\
(543)\end{array}$ & $\begin{array}{l}-.02 \\
{[-.13, .10]} \\
(308)\end{array}$ & $\begin{array}{l}.01 \\
{[-.08, .10]} \\
(485)\end{array}$ & $\begin{array}{l}-.02 \\
{[-.10, .07]} \\
(552)\end{array}$ & $\begin{array}{l}-.01 \\
{[-.12, .10]} \\
(315)\end{array}$ \\
\hline $\begin{array}{l}\text { Underachievement } \\
\text { (threshold }|5| \text { ) }\end{array}$ & $\begin{array}{l}-.08 \\
{[-.16, .00]} \\
(537)\end{array}$ & $\begin{array}{l}-.05 \\
{[-.13, .02]} \\
(649)\end{array}$ & $\begin{array}{l}-.05 \\
{[-.13, .03]} \\
(559)\end{array}$ & $\begin{array}{l}-.04 \\
{[-.15, .07]} \\
(316)\end{array}$ & $\begin{array}{l}-.07 \\
{[-.16, .03]} \\
(458)\end{array}$ & $\begin{array}{l}-.12 \\
{[-.20,-.03]} \\
(543)\end{array}$ & $\begin{array}{l}-.03 \\
{[-.14, .08]} \\
(308)\end{array}$ & $\begin{array}{l}-.14 \\
{[-.23,-.05]} \\
(485)\end{array}$ & $\begin{array}{l}-.12 \\
{[-.20,-.03]} \\
(552)\end{array}$ & $\begin{array}{l}-.11 \\
{[-.22, .00]} \\
(315)\end{array}$ \\
\hline $\begin{array}{l}\text { Overachievement } \\
\text { (threshold }|5| \text { ) }\end{array}$ & $\begin{array}{l}-.06 \\
{[-.15, .02]} \\
(537)\end{array}$ & $\begin{array}{l}-.05 \\
{[-.13, .03]} \\
(649)\end{array}$ & $\begin{array}{l}-.05 \\
{[-.13, .04]} \\
(559)\end{array}$ & $\begin{array}{l}.07 \\
{[-.05, .18]} \\
(316)\end{array}$ & $\begin{array}{l}-.09 \\
{[-.18, .00]} \\
(458)\end{array}$ & $\begin{array}{l}.02 \\
{[-.07, .10]} \\
(543)\end{array}$ & $\begin{array}{l}.05 \\
{[-.06, .16]} \\
(308)\end{array}$ & $\begin{array}{l}-.03 \\
{[-.12, .06]} \\
(485)\end{array}$ & $\begin{array}{l}-.03 \\
{[-.11, .06]} \\
(552)\end{array}$ & $\begin{array}{l}.04 \\
{[-.08, .15]} \\
(315)\end{array}$ \\
\hline Extraversion & $\begin{array}{l}.09 \\
{[.03, .15]} \\
(1,132)\end{array}$ & $\begin{array}{l}.09 \\
{[.03, .15]} \\
(1,078)\end{array}$ & $\begin{array}{l}.09 \\
{[.02, .15]} \\
(804)\end{array}$ & $\begin{array}{l}.10 \\
{[.00, .19]} \\
(429)\end{array}$ & $\begin{array}{l}.10 \\
{[.03, .18]} \\
(695)\end{array}$ & $\begin{array}{l}.02 \\
{[-.05, .09]} \\
(772)\end{array}$ & $\begin{array}{l}.05 \\
{[-.05, .15]} \\
(415)\end{array}$ & $\begin{array}{l}-.01 \\
{[-.08, .06]} \\
(763)\end{array}$ & $\begin{array}{l}-.03 \\
{[-.10, .04]} \\
(795)\end{array}$ & $\begin{array}{l}-.05 \\
{[-.14, .05]} \\
(427)\end{array}$ \\
\hline Agreeableness & $\begin{array}{l}.13 \\
{[.07, .19]} \\
(1,133)\end{array}$ & $\begin{array}{l}.16 \\
{[.10, .22]} \\
(1,080)\end{array}$ & $\begin{array}{l}.12 \\
{[.05, .18]} \\
(805)\end{array}$ & $\begin{array}{l}.08 \\
{[-.02, .17]} \\
(429)\end{array}$ & $\begin{array}{l}.08 \\
{[.00, .15]} \\
(696)\end{array}$ & $\begin{array}{l}.09 \\
{[.02, .16]} \\
(774)\end{array}$ & $\begin{array}{l}.14 \\
{[.04, .23]} \\
(415)\end{array}$ & $\begin{array}{l}.13 \\
{[.06, .20]} \\
(764)\end{array}$ & $\begin{array}{l}.11 \\
{[.04, .18]} \\
(797)\end{array}$ & $\begin{array}{l}.10 \\
{[.01, .19]} \\
(427)\end{array}$ \\
\hline Conscientiousness & $\begin{array}{l}.16 \\
{[.10, .21]} \\
(1,135)\end{array}$ & $\begin{array}{l}.13 \\
{[.07, .19]} \\
(1,082)\end{array}$ & $\begin{array}{l}.09 \\
{[.02, .16]} \\
(807)\end{array}$ & $\begin{array}{l}.05 \\
{[-.05, .14]} \\
(430)\end{array}$ & $\begin{array}{l}.08 \\
{[.01, .15]} \\
(697)\end{array}$ & $\begin{array}{l}.09 \\
{[.02, .16]} \\
(775)\end{array}$ & $\begin{array}{l}.12 \\
{[.02, .21]} \\
(416)\end{array}$ & $\begin{array}{l}.05 \\
{[-.02, .12]} \\
(765)\end{array}$ & $\begin{array}{l}.08 \\
{[.01, .15]} \\
(798)\end{array}$ & $\begin{array}{l}.07 \\
{[-.02, .17]} \\
(428)\end{array}$ \\
\hline
\end{tabular}




\begin{tabular}{|c|c|c|c|c|c|c|c|c|c|c|}
\hline & \multicolumn{10}{|c|}{$r[95 \% \mathrm{CI}]$ (pairwise $N$ ) } \\
\hline & \multicolumn{4}{|c|}{ General life satisfaction } & \multicolumn{3}{|c|}{ Job satisfaction } & \multicolumn{3}{|c|}{ Income satisfaction } \\
\hline & $\mathrm{t}_{-1}$ & $\mathrm{t}_{0}$ & $\mathrm{t}_{1}$ & $\mathrm{t}_{2}$ & $\mathrm{t}_{0}$ & $\mathrm{t}_{1}$ & $\mathrm{t}_{2}$ & $\mathrm{t}_{0}$ & $\mathrm{t}_{1}$ & $\mathrm{t}_{2}$ \\
\hline Emotional & .14 & .14 & .16 & .20 & .11 & .07 & .13 & .04 & .04 & .07 \\
\hline \multirow[t]{2}{*}{ Stability } & {$[.09, .20]$} & {$[.08, .19]$} & {$[.09, .22]$} & {$[.11, .29]$} & {$[.04, .19]$} & {$[-.00, .14]$} & {$[.03, .22]$} & {$[-.03, .12]$} & {$[-.04, .10]$} & {$[-.02, .17]$} \\
\hline & $(1,136)$ & $(1,084)$ & $(808)$ & $(431)$ & $(698)$ & $(776)$ & $(417)$ & $(766)$ & (799) & $(429)$ \\
\hline \multirow{3}{*}{ Openness } & .08 & .08 & .02 & .02 & .07 & .02 & -.03 & .06 & .03 & .01 \\
\hline & {$[.02, .14]$} & {$[.02, .14]$} & {$[-.05, .09]$} & {$[-.08, .11]$} & {$[-.01, .14]$} & {$[-.05, .09]$} & {$[-.13, .07]$} & {$[-.02, .13]$} & {$[-.04, .10]$} & {$[-.09, .10]$} \\
\hline & $(1,121)$ & $(1,076)$ & $(801)$ & (429) & $(692)$ & (769) & $(415)$ & $(760)$ & $(792)$ & $(427)$ \\
\hline \multirow[t]{3}{*}{ Parental SES } & .03 & .02 & .01 & -.03 & -.04 & -.14 & -.23 & .15 & .17 & .23 \\
\hline & {$[-.06, .12]$} & {$[-.07, .11]$} & {$[-.10, .12]$} & {$[-.20, .13]$} & {$[-.17, .08]$} & {$[-.25,-.03]$} & {$[-.38,-.06]$} & {$[.03, .27]$} & {$[.06, .28]$} & {$[.06, .38]$} \\
\hline & $(464)$ & (443) & (304) & (140) & (246) & $(291)$ & $(136)$ & (269) & (297) & $(140)$ \\
\hline Migration & .10 & .05 & .07 & .01 & .06 & -.05 & .04 & .01 & .01 & -.00 \\
\hline \multirow{2}{*}{ background } & {$[.04, .16]$} & {$[-.01, .11]$} & {$[00 ., .14]$} & {$[-.09, .10]$} & {$[-.02, .13]$} & {$[-.12, .02]$} & {$[-.05, .14]$} & {$[-.07, .08]$} & {$[-.06, .08]$} & {$[-.09, .09]$} \\
\hline & $(1,141)$ & $(1,089)$ & $(815)$ & $(437)$ & (703) & $(784)$ & $(423)$ & $(772)$ & $(807)$ & $(435)$ \\
\hline \multirow[t]{3}{*}{ Female } & -.08 & -.05 & -.03 & -.08 & -.05 & -.08 & -.04 & -.02 & -.02 & -.06 \\
\hline & {$[-.13,-.02]$} & {$[-.11, .01]$} & {$[-.10, .04]$} & {$[-.17, .01]$} & {$[-.13, .02]$} & {$[-.15,-.01]$} & {$[-.14, .06]$} & {$[-.09, .05]$} & {$[-.09, .05]$} & {$[-.15, .04]$} \\
\hline & $(1,141)$ & $(1,089)$ & $(815)$ & (437) & $(703)$ & $(784)$ & (423) & $(772)$ & (807) & (435) \\
\hline \multirow{3}{*}{$\begin{array}{l}\text { VET entry 2006-2009 } \\
\text { (Pre-economic crisis) }\end{array}$} & -.07 & -.06 & -.09 & -.06 & -.05 & -.03 & -.07 & -.09 & -.09 & -.12 \\
\hline & {$[-.13,-.01]$} & {$[-.12,-.00]$} & {$[-.16,-.02]$} & {$[-.15, .03]$} & {$[-.12, .03]$} & {$[-.10, .04]$} & {$[-.16, .03]$} & {$[-.16,-.02]$} & {$[-.15,-.02]$} & {$[-.21,-.03]$} \\
\hline & $(1,141)$ & $(1,089)$ & $(815)$ & $(437)$ & $(703)$ & (784) & $(423)$ & $(772)$ & $(807)$ & $(435)$ \\
\hline \multirow{3}{*}{$\begin{array}{l}\text { VET entry 2010-2013 } \\
\text { (Post-economic crisis } \\
\text { recovery) }\end{array}$} & .05 & .00 & .03 & -.00 & .00 & .02 & .02 & .04 & .01 & .04 \\
\hline & {$[-.01, .11]$} & {$[-.06, .06]$} & {$[-.04, .10]$} & {$[-.10, .09]$} & {$[-.07, .08]$} & {$[-.05, .09]$} & {$[-.08, .11]$} & {$[-.03, .11]$} & {$[-.06, .08]$} & {$[-.06, .13]$} \\
\hline & $(1,141)$ & $(1,089)$ & $(815)$ & $(437)$ & $(703)$ & $(784)$ & $(423)$ & $(772)$ & $(807)$ & $(435)$ \\
\hline \multirow{3}{*}{$\begin{array}{l}\text { VET entry before } \\
\text { first interview }\end{array}$} & -.04 & .13 & .06 & .00 & -.01 & -.03 & -.02 & -.01 & .07 & .06 \\
\hline & {$[-.10, .01]$} & {$[.07, .18]$} & {$[-.01, .13]$} & {$[-.09, .10]$} & {$[-.08, .07]$} & {$[-.10, .04]$} & {$[-.11, .08]$} & {$[-.08, .06]$} & {$[-.00, .14]$} & {$[-.03, .16]$} \\
\hline & $(1,141)$ & $(1,089)$ & $(815)$ & $(437)$ & $(703)$ & $(784)$ & (423) & $(772)$ & $(807)$ & $(435)$ \\
\hline
\end{tabular}

Note. SES = socioeconomic status, VET $=$ vocational education and training. $N=1,536$. 


\section{Appendix C}

\section{Defining the Three Domains of Subjective Well-Being Examined in the Study}

General life satisfaction refers to the global assessment of the overall quality (i.e., all aspects) of a person's life (e.g., Diener, 1984; Veenhoven, 1996). It can be regarded as the cognitive-evaluative component of subjective well-being (e.g., Diener, 1984).

Spector (1997) defined job satisfaction as "the extent to which people like [...] or dislike [...] their jobs" (p. 2), and the way they feel about different aspects of their jobs, for example, their treatment at work or the demands and challenges of the job. Job satisfaction and income are the two main outcome measures of career success (for a meta-analysis, see $\mathrm{Ng}$ et al., 2005), and experiencing high job satisfaction is crucial for further career progression (e.g., Medici et al., 2020).

Finally, income satisfaction can be understood simply as the degree to which people are satisfied with their personal income. According to the effort-reward imbalance (ERI) model (Siegrist, 1996), an imbalance between high work effort and low rewards (e.g., through income or recognition) is perceived as unfair, and results in negative feelings (e.g., disappointment, dissatisfaction) and poor health in the long term because of continuous strain reactions in the autonomic nervous system (Siegrist et al., 2004). Thus, low income satisfaction can prove problematic for the further life course and for career progression.

\section{References}

Diener, E. (1984). Subjective well-being. Psychological Bulletin, 95(3), 542-575. https://doi.org/10.1037/0033-2909.95.3.542

Medici G., Tschopp, C., Grote, G., \& Hirschi, A. (2020). Grass roots of occupational change: Understanding mobility in vocational careers. Journal of Vocational Behavior, 122, 103480. https://doi.org/10.1016/j.jvb.2020.103480 
Ng, T. W. H., Eby, L. T., Sorensen, K. L., \& Feldman, D. C. (2005). Predictors of objective and subjective career success. A meta-analysis. Personnel Psychology, 58(2), 367-408. https://doi.org/10.1111/j.1744-6570.2005.00515.x

Siegrist, J. (1996). Adverse health effects of high-effort/low-reward conditions. Journal of Occupational Health Psychology, 1(1), 27-41. https://doi.org/10.1037/1076-8998.1.1.27

Siegrist, J., Starke, D., Chandola, T., Godin, I., Marmot, M., Niedhammer, I., \& Peter, R. (2004). The measurement of effort-reward imbalance at work: European comparisons. Social Science \& Medicine, 58(8), 1483-1499. https://doi.org/10.1016/S02779536(03)00351-4

Spector, P. E. (1997). Job satisfaction: Application, assessment, causes and consequences. SAGE Publications.

Veenhoven, R. (1996). The study of life satisfaction. In W. E. Saris, R. Scheenhoven, A. C. Scherpenzeel, \& B. Bunting (Eds.), A comparative study of satisfaction with life in Europe (pp. 1-48). Eötvös University Press. 


\section{Appendix D}

Unstandardized Coefficients of the Latent Growth Curve Models for General Life Satisfaction

Regressed on the Aspiration-Attainment Gap, the Covariates, and Pre-VET General Life Satisfaction (Model IV)

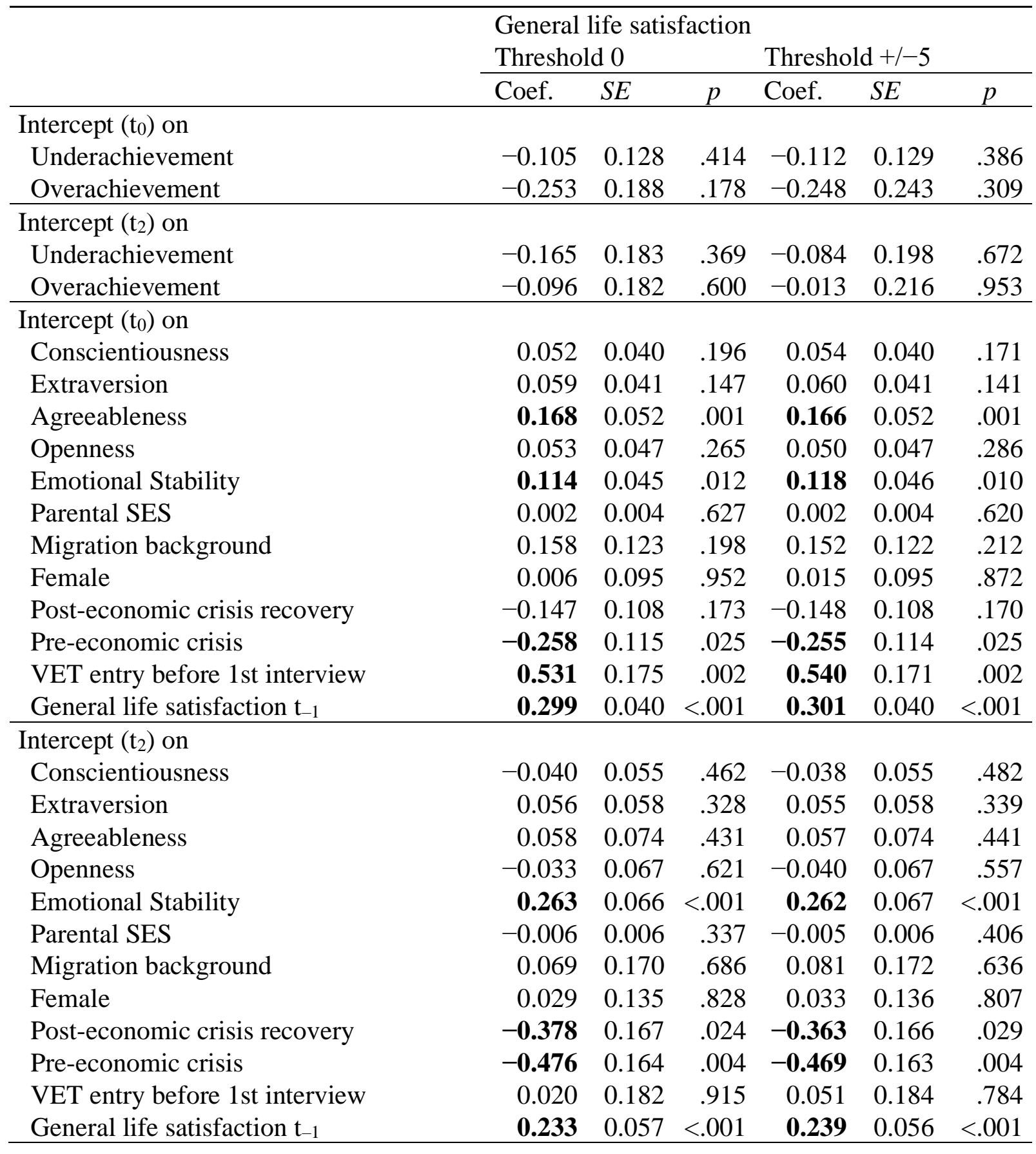




\begin{tabular}{|c|c|c|c|c|c|c|}
\hline & \multicolumn{3}{|c|}{$\begin{array}{l}\text { General life satisfaction } \\
\text { Threshold } 0\end{array}$} & \multicolumn{3}{|c|}{ Threshold $+/-5$} \\
\hline & Coef. & $S E$ & $p$ & Coef. & $S E$ & $p$ \\
\hline \multicolumn{7}{|l|}{ Linear slope on } \\
\hline Underachievement & -0.030 & 0.111 & .788 & 0.014 & 0.116 & .905 \\
\hline Overachievement & 0.079 & 0.115 & .494 & 0.118 & 0.135 & .383 \\
\hline \multicolumn{7}{|l|}{ Linear slope on } \\
\hline Conscientiousness & -0.046 & 0.032 & .155 & -0.046 & 0.032 & .149 \\
\hline Extraversion & -0.001 & 0.033 & .964 & -0.002 & 0.033 & .943 \\
\hline Agreeableness & -0.055 & 0.043 & .202 & -0.055 & 0.043 & .202 \\
\hline Openness & -0.043 & 0.040 & .284 & -0.045 & 0.039 & .255 \\
\hline Emotional Stability & 0.075 & 0.039 & .058 & 0.072 & 0.040 & .067 \\
\hline Parental SES & -0.004 & 0.003 & .281 & -0.003 & 0.003 & .326 \\
\hline Migration background & -0.045 & 0.105 & .670 & -0.035 & 0.105 & .736 \\
\hline Female & 0.012 & 0.080 & .882 & 0.009 & 0.080 & .911 \\
\hline Post-economic crisis recovery & -0.115 & 0.097 & .235 & -0.108 & 0.097 & .266 \\
\hline Pre-economic crisis & -0.109 & 0.099 & .271 & -0.107 & 0.098 & .276 \\
\hline VET entry before 1 st interview & -0.256 & 0.100 & .010 & -0.245 & 0.100 & .015 \\
\hline General life satisfaction $\mathrm{t}_{-1}$ & -0.033 & 0.035 & .342 & -0.031 & 0.034 & .368 \\
\hline \multicolumn{7}{|l|}{ Intercept-slope } \\
\hline Covariance $\left(\mathrm{t}_{0}\right)$ & -0.178 & 0.125 & .154 & $-\mathbf{0 . 1 7 5}$ & 0.068 & .010 \\
\hline Covariance $\left(\mathrm{t}_{2}\right)$ & 0.306 & 0.158 & .053 & 0.303 & 0.157 & .054 \\
\hline \multicolumn{7}{|l|}{ Means } \\
\hline Underachievement & 0.347 & 0.016 & $<.001$ & 0.289 & 0.015 & $<.001$ \\
\hline Overachievement & 0.152 & 0.013 & $<.001$ & 0.096 & 0.011 & $<.001$ \\
\hline Conscientiousness & 4.950 & 0.028 & $<.001$ & 4.950 & 0.028 & $<.001$ \\
\hline Extraversion & 4.899 & 0.032 & $<.001$ & 4.900 & 0.032 & $<.001$ \\
\hline Agreeableness & 5.351 & 0.024 & $<.001$ & 5.351 & 0.024 & $<.001$ \\
\hline Openness & 4.638 & 0.026 & $<.001$ & 4.638 & 0.026 & $<.001$ \\
\hline Emotional Stability & 4.047 & 0.029 & $<.001$ & 4.047 & 0.029 & $<.001$ \\
\hline Parental SES & 43.160 & 1.105 & $<.001$ & 42.953 & 1.120 & $<.001$ \\
\hline Migration background & 0.189 & 0.010 & $<.001$ & 0.189 & 0.010 & $<.001$ \\
\hline Female & 0.452 & 0.013 & $<.001$ & 0.452 & 0.013 & $<.001$ \\
\hline Post-economic crisis recovery & 0.339 & 0.012 & $<.001$ & 0.339 & 0.012 & $<.001$ \\
\hline Pre-economic crisis & 0.213 & 0.010 & $<.001$ & 0.213 & 0.010 & $<.001$ \\
\hline VET entry before 1 st interview & 0.233 & 0.011 & $<.001$ & 0.233 & 0.011 & $<.001$ \\
\hline General life satisfaction $\mathrm{t}_{-1}$ & 7.507 & 0.116 & $<.001$ & 7.503 & 0.114 & $<.001$ \\
\hline \multicolumn{7}{|l|}{ Intercepts } \\
\hline Intercept $\left(\mathrm{t}_{0}\right)$ & 3.267 & 0.483 & $<.001$ & 3.218 & 0.475 & $<.001$ \\
\hline Intercept $\left(\mathrm{t}_{2}\right)$ & 4.876 & 0.687 & $<.001$ & 4.779 & 0.676 & $<.001$ \\
\hline Linear slope & 0.805 & 0.416 & .053 & 0.780 & 0.409 & .056 \\
\hline
\end{tabular}




\begin{tabular}{|c|c|c|c|c|c|c|}
\hline & \multicolumn{6}{|c|}{ General life satisfaction } \\
\hline & Coef. & $S E$ & $p$ & Coef. & $S E$ & $p$ \\
\hline \multicolumn{7}{|l|}{ Variances } \\
\hline Underachievement & 0.224 & 0.006 & $<.001$ & 0.201 & 0.007 & $<.001$ \\
\hline Overachievement & 0.125 & 0.009 & $<.001$ & 0.083 & 0.009 & $<.001$ \\
\hline Conscientiousness & 1.215 & 0.042 & $<.001$ & 1.215 & 0.042 & $<.001$ \\
\hline Extraversion & 1.552 & 0.052 & $<.001$ & 1.552 & 0.052 & $<.001$ \\
\hline Agreeableness & 0.856 & 0.032 & $<.001$ & 0.856 & 0.032 & $<.001$ \\
\hline Openness & 0.993 & 0.033 & $<.001$ & 0.993 & 0.033 & $<.001$ \\
\hline Emotional Stability & 1.309 & 0.044 & $<.001$ & 1.309 & 0.044 & $<.001$ \\
\hline Parental SES & 347.554 & 14.902 & $<.001$ & 347.111 & 14.519 & $<.001$ \\
\hline Migration background & 0.154 & 0.006 & $<.001$ & 0.154 & 0.006 & $<.001$ \\
\hline Female & 0.248 & 0.001 & $<.001$ & 0.248 & 0.001 & $<.001$ \\
\hline Post-economic crisis recovery & 0.224 & 0.004 & $<.001$ & 0.224 & 0.004 & $<.001$ \\
\hline Pre-economic crisis & 0.168 & 0.006 & $<.001$ & 0.168 & 0.006 & $<.001$ \\
\hline VET entry before 1 st interview & 0.179 & 0.006 & $<.001$ & 0.179 & 0.006 & $<.001$ \\
\hline General life satisfaction $\mathrm{t}_{-1}$ & 2.546 & 0.160 & $<.001$ & 2.549 & 0.160 & $<.001$ \\
\hline \multicolumn{7}{|l|}{ Residual variances } \\
\hline General life satisfaction $t_{0}$ & 1.165 & 0.213 & $<.001$ & 1.169 & 0.163 & $<.001$ \\
\hline General life satisfaction $t_{1}$ & 1.270 & 0.135 & $<.001$ & 1.275 & 0.137 & $<.001$ \\
\hline General life satisfaction $t_{2}$ & 1.112 & 0.258 & $<.001$ & 1.113 & 0.223 & $<.001$ \\
\hline Intercept $\left(\mathrm{t}_{0}\right)$ & 0.968 & 0.211 & $<.001$ & 0.964 & 0.134 & $<.001$ \\
\hline Intercept $\left(\mathrm{t}_{2}\right)$ & 1.224 & 0.277 & $<.001$ & 1.220 & 0.276 & $<.001$ \\
\hline Linear slope & 0.242 & 0.116 & .038 & 0.239 & 0.053 & $<.001$ \\
\hline
\end{tabular}

Note . VET $=$ vocational education and training. $N=1,536$. Regression coefficients and inter-

cept-slope covariances significant at the $p<.05$ level are in bold type. Fit indices of the model with aspiration-attainment gap (AAG) threshold of $0: \chi^{2}(15)=4.617, p=.995$, comparative fit index $(\mathrm{CFI})=1.000$, root-mean-square error of approximation $(\mathrm{RMSEA})=.000$, standardized root-mean-square residual $(\mathrm{SRMR})=.005$, Bayesian information criterion $(\mathrm{BIC})=68,819.882$. Fit indices of the model with AAG threshold of $|5|$ : $\chi^{2}(15)=5.227, p=.990, \mathrm{CFI}=1.000, \mathrm{RMSEA}=.000, \mathrm{SRMR}=.005, \mathrm{BIC}=68,270.625$. 


\section{Appendix E}

\section{Depiction of the Third Latent Growth Curve Model (Model III)}

A

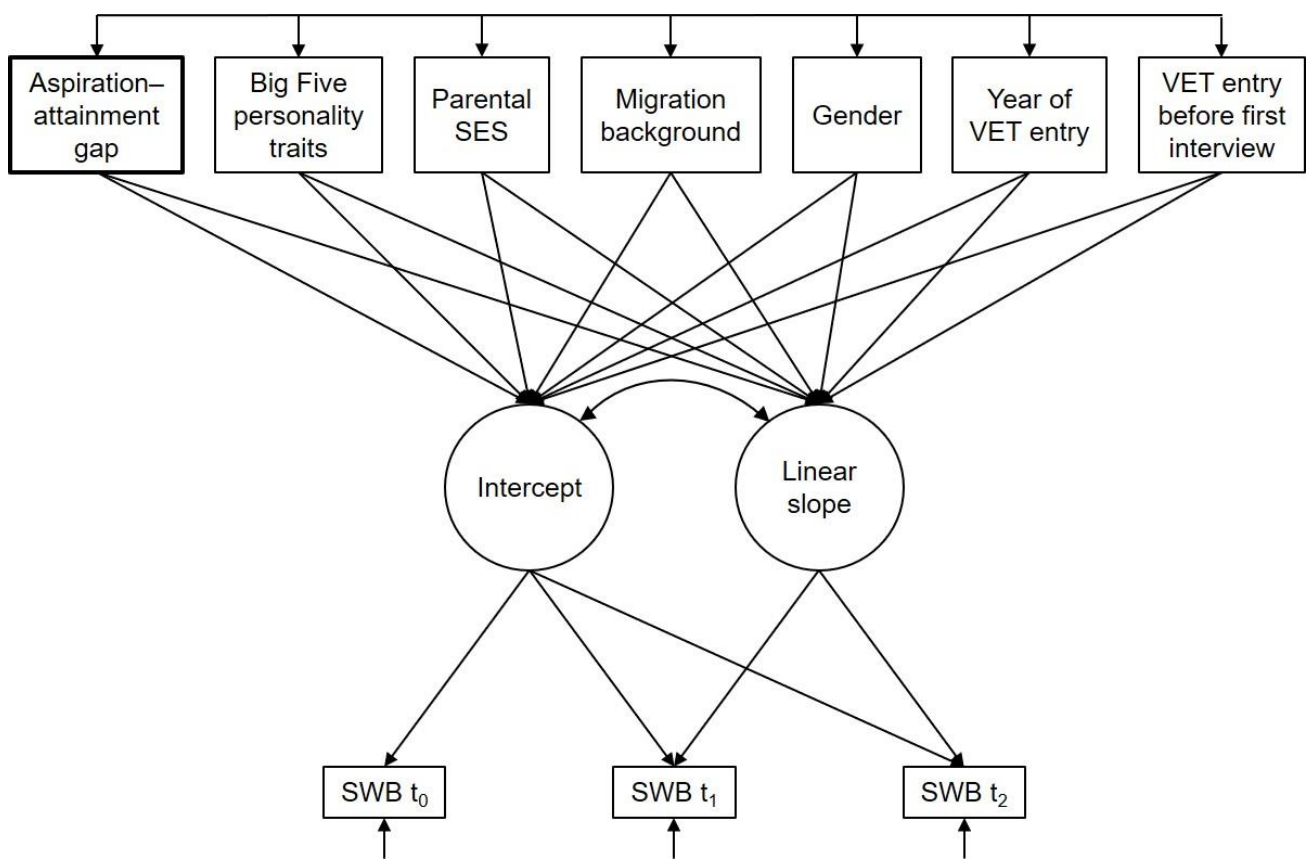

B

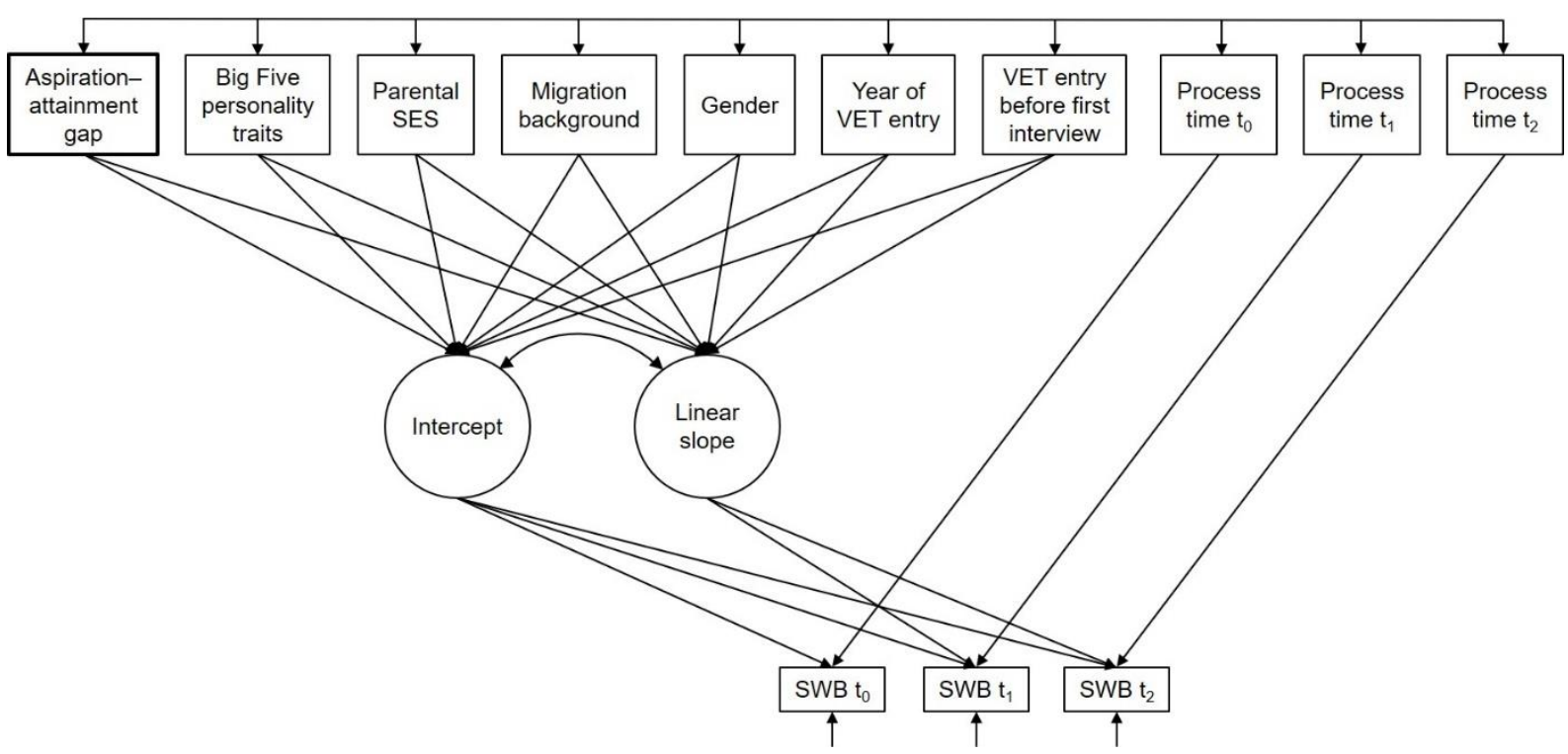

Note . VET = vocational education and training, $\mathrm{SWB}=$ subjective well-being. A: Model with time-invariant predictors. B: Model with time-invariant and time-varying predictors. 


\section{Appendix F}

Percentages of the Distribution of Aspirations and Attainment

A

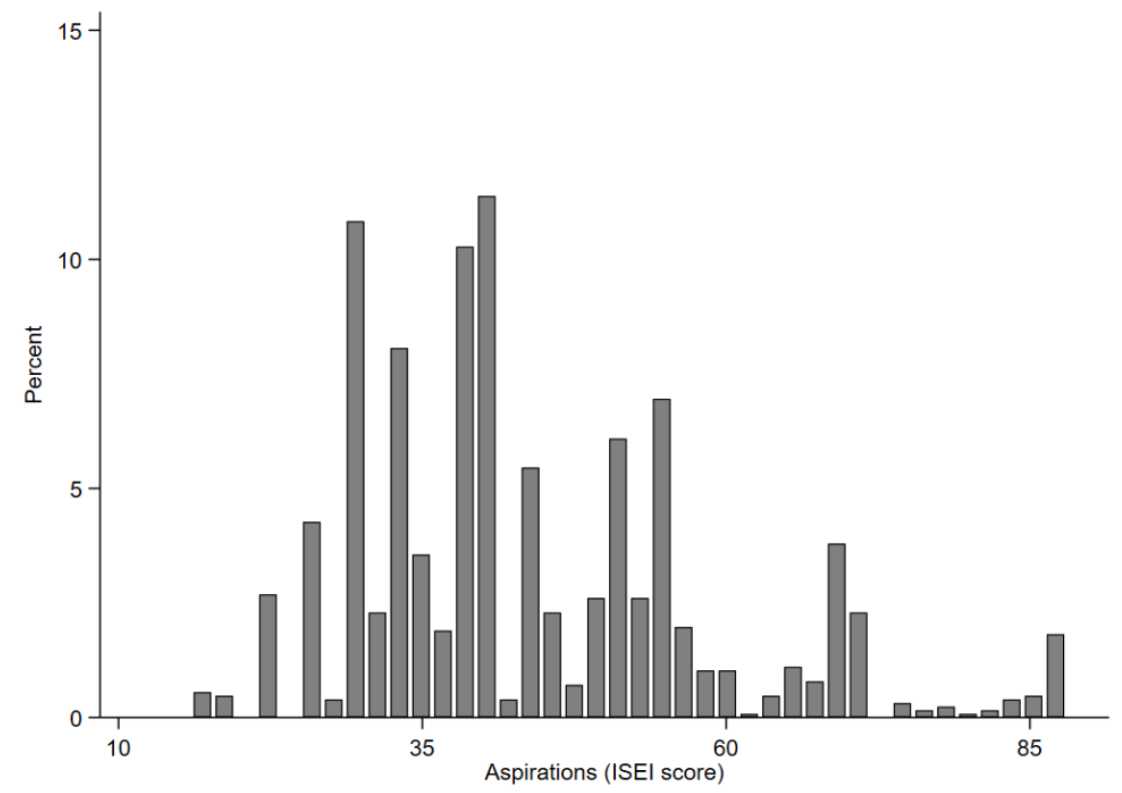

B

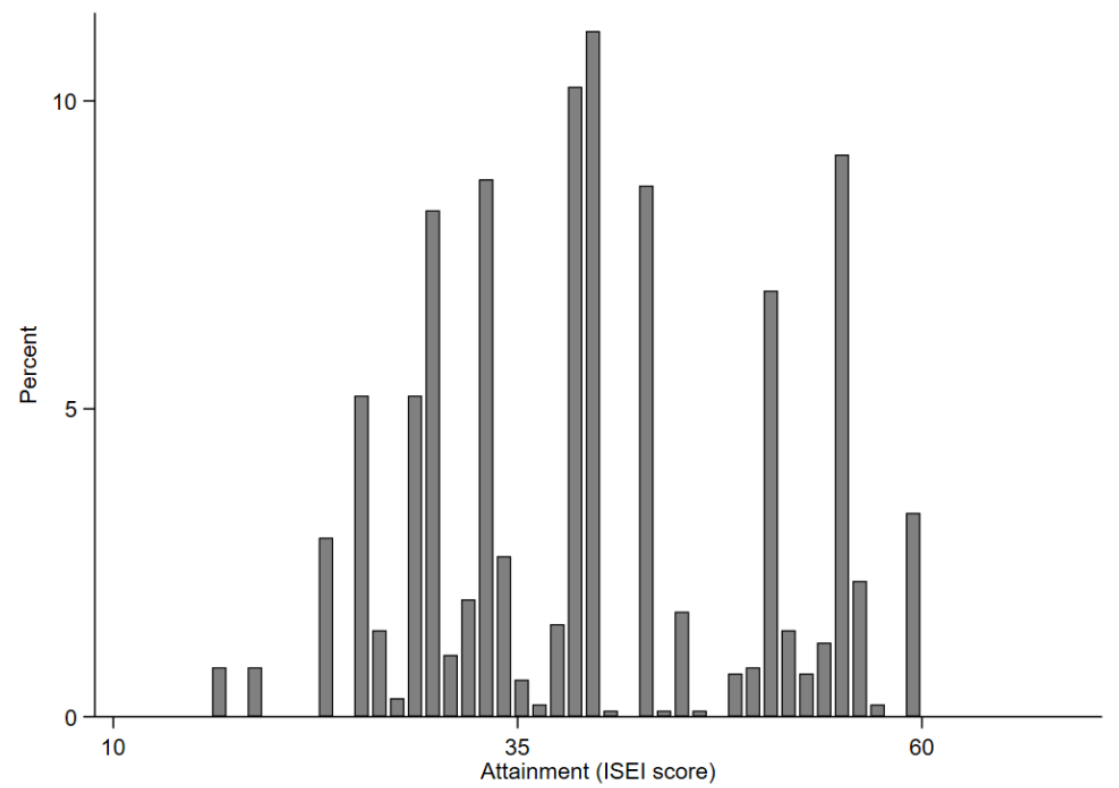

Note. ISEI = International Socio-Economic Index of Occupational Status. A: Distribution of aspirations $(N=1,265)$. B: Distribution of attainment $(N=997)$. 


\section{Appendix G}

Unstandardized Coefficients of the Latent Growth Curve Models for Three Domains of Subjective Well-Being Regressed on the Aspiration-Attainment

Gap (Model II)

\begin{tabular}{|c|c|c|c|c|c|c|c|c|c|c|c|c|c|c|c|c|c|c|}
\hline & \multicolumn{6}{|c|}{ General life satisfaction } & \multicolumn{6}{|c|}{ Job satisfaction } & \multicolumn{6}{|c|}{ Income satisfaction } \\
\hline & \multicolumn{2}{|c|}{ Threshold 0} & \multicolumn{4}{|c|}{ Threshold $+/-5$} & \multicolumn{3}{|c|}{ Threshold 0} & \multicolumn{3}{|c|}{ Threshold $+/-5$} & \multicolumn{3}{|c|}{ Threshold 0} & \multicolumn{3}{|c|}{ Threshold $+/-5$} \\
\hline & Coef. & $S E$ & $p$ & Coef. & $S E$ & $p$ & Coef. & $S E$ & $p$ & Coef. & $S E$ & $p$ & Coef. & $S E$ & $p$ & Coef. & $S E$ & $p$ \\
\hline \multicolumn{19}{|l|}{ Intercept $\left(\mathrm{t}_{0}\right)$ on } \\
\hline Underachievement & -0.274 & 0.130 & .035 & -0.269 & 0.133 & .043 & -0.336 & 0.167 & .044 & -0.369 & 0.175 & .035 & -0.612 & 0.239 & .010 & -0.864 & 0.244 & $<.001$ \\
\hline Overachievement & -0.474 & 0.190 & .013 & -0.400 & 0.249 & .109 & -0.651 & 0.264 & .014 & -0.570 & 0.338 & .092 & -0.439 & 0.323 & .173 & -0.792 & 0.408 & .052 \\
\hline \multicolumn{19}{|l|}{ Intercept $\left(\mathrm{t}_{2}\right)$ on } \\
\hline Underachievement & -0.207 & 0.187 & .267 & -0.101 & 0.200 & .614 & -0.420 & 0.223 & .060 & -0.247 & 0.242 & .307 & -0.353 & 0.260 & .174 & -0.421 & 0.273 & .123 \\
\hline Overachievement & -0.092 & 0.187 & .622 & 0.071 & 0.219 & .746 & -0.112 & 0.299 & .709 & 0.272 & 0.316 & .390 & -0.240 & 0.344 & .486 & -0.146 & 0.398 & .713 \\
\hline \multicolumn{19}{|l|}{ Linear slope on } \\
\hline Underachievement & 0.033 & 0.107 & .757 & 0.084 & 0.113 & .458 & -0.042 & 0.127 & .741 & 0.061 & 0.135 & .650 & 0.130 & 0.159 & .417 & 0.221 & 0.168 & .187 \\
\hline Overachievement & 0.191 & 0.116 & .099 & 0.235 & 0.138 & .088 & 0.270 & 0.185 & .145 & 0.421 & 0.215 & .050 & 0.100 & 0.193 & .605 & 0.323 & 0.215 & .133 \\
\hline \multicolumn{19}{|l|}{ Intercept-slope } \\
\hline Covariance $\left(\mathrm{t}_{0}\right)$ & -0.241 & 0.143 & .093 & -0.234 & 0.146 & .108 & -0.477 & 0.293 & .103 & -0.436 & 0.298 & .144 & -1.125 & 0.364 & .002 & -1.066 & 0.424 & .012 \\
\hline Covariance $\left(\mathrm{t}_{2}\right)$ & 0.336 & 0.180 & .061 & 0.330 & 0.179 & .066 & 0.559 & 0.292 & .055 & 0.528 & 0.296 & .075 & 0.549 & 0.363 & .130 & 0.560 & 0.364 & .124 \\
\hline \multicolumn{19}{|l|}{ Means } \\
\hline Underachievement & 0.333 & 0.016 & $<.001$ & 0.276 & 0.015 & $<.001$ & 0.333 & 0.016 & $<.001$ & 0.276 & 0.015 & $<.001$ & 0.337 & 0.016 & $<.001$ & 0.282 & 0.015 & $<.001$ \\
\hline Overachievement & 0.149 & 0.013 & $<.001$ & 0.094 & 0.011 & $<.001$ & 0.149 & 0.013 & $<.001$ & 0.094 & 0.011 & $<.001$ & 0.150 & 0.013 & $<.001$ & 0.095 & 0.011 & $<.001$ \\
\hline \multicolumn{19}{|l|}{ Intercepts } \\
\hline Intercept $\left(\mathrm{t}_{0}\right)$ & 7.884 & 0.070 & $<.001$ & 7.834 & 0.063 & $<.001$ & 8.132 & 0.099 & $<.001$ & 8.078 & 0.087 & $<.001$ & 6.392 & 0.144 & $<.001$ & 6.438 & 0.122 & $<.001$ \\
\hline Intercept $\left(\mathrm{t}_{2}\right)$ & 7.455 & 0.092 & $<.001$ & 7.398 & 0.083 & $<.001$ & 7.336 & 0.125 & $<.001$ & 7.229 & 0.114 & $<.001$ & 5.810 & 0.145 & $<.001$ & 5.786 & 0.131 & $<.001$ \\
\hline Linear slope & -0.214 & 0.055 & $<.001$ & -0.218 & 0.049 & $<.001$ & -0.398 & 0.079 & $<.001$ & -0.424 & 0.070 & $<.001$ & -0.291 & 0.093 & .002 & -0.326 & 0.081 & $<.001$ \\
\hline
\end{tabular}




\begin{tabular}{|c|c|c|c|c|c|c|c|c|c|c|c|c|c|c|c|c|c|c|}
\hline & \multicolumn{6}{|c|}{ General life satisfaction } & \multicolumn{6}{|c|}{ Job satisfaction } & \multicolumn{6}{|c|}{ Income satisfaction } \\
\hline & \multicolumn{3}{|c|}{ Threshold 0} & \multicolumn{3}{|c|}{ Threshold $+/-5$} & \multicolumn{3}{|c|}{ Threshold 0} & \multicolumn{3}{|c|}{ Threshold $+/-5$} & \multicolumn{3}{|c|}{ Threshold 0} & \multicolumn{3}{|c|}{ Threshold $+/-5$} \\
\hline & Coef. & $S E$ & $p$ & Coef. & $S E$ & $p$ & Coef. & $S E$ & $p$ & Coef. & $S E$ & $p$ & Coef. & $S E$ & $p$ & Coef. & $S E$ & $p$ \\
\hline \multicolumn{19}{|l|}{ Variances } \\
\hline Underachieve & 0.224 & 0.006 & $<.001$ & 0.201 & 0.007 & $<.001$ & 0.223 & 0.006 & $<.001$ & 0.201 & 0.007 & $<.001$ & 0.223 & 0.006 & $<.001$ & 0.200 & 0.007 & $<.001$ \\
\hline Overachievement & 0.125 & 0.009 & $<.001$ & 0.083 & 0.009 & $<.001$ & 0.125 & 0.009 & $<.001$ & 0.083 & 0.009 & $<.001$ & 0.125 & 0.009 & $<.001$ & 0.083 & 0.009 & $<.001$ \\
\hline \multicolumn{19}{|l|}{ Residual variances } \\
\hline Satisfaction $\mathrm{t}_{0}$ & 1.192 & 0.232 & $<.001$ & 1.201 & 0.234 & $<.001$ & 1.078 & 0.452 & .017 & 1.141 & 0.462 & .014 & 1.819 & 0.530 & .001 & 1.854 & 0.594 & .002 \\
\hline Satisfaction $\mathrm{t}_{1}$ & 1.272 & 0.141 & $<.001$ & 1.277 & 0.143 & $<.001$ & 2.248 & 0.251 & $<.001$ & 2.248 & 0.252 & $<.001$ & 2.656 & 0.241 & $<.001$ & 2.659 & 0.242 & $<.001$ \\
\hline Satisfaction $\mathrm{t}_{2}$ & 1.090 & 0.268 & $<.001$ & 1.091 & 0.267 & $<.001$ & 1.692 & 0.451 & $<.001$ & 1.724 & 0.457 & $<.001$ & 1.726 & 0.535 & .001 & 1.716 & 0.559 & .002 \\
\hline Intercept $\left(\mathrm{t}_{0}\right)$ & 1.335 & 0.236 & $<.001$ & 1.333 & 0.238 & $<.001$ & 2.393 & 0.468 & $<.001$ & 2.351 & 0.470 & $<.001$ & 5.478 & 0.573 & $<.001$ & 5.353 & 0.657 & $<.001$ \\
\hline Intercept $\left(\mathrm{t}_{2}\right)$ & 1.524 & 0.317 & $<.001$ & 1.524 & 0.316 & $<.001$ & 2.557 & 0.475 & $<.001$ & 2.536 & 0.475 & $<.001$ & 4.326 & 0.578 & $<.001$ & 4.339 & 0.582 & $<.001$ \\
\hline Linear slope & 0.289 & 0.133 & .030 & 0.282 & 0.134 & .035 & 0.518 & 0.248 & .037 & 0.482 & 0.255 & .058 & 0.837 & 0.305 & .006 & 0.813 & 0.349 & .020 \\
\hline
\end{tabular}

Note. $N=1,536$. Regression coefficients and intercept-slope covariances significant at the $p<.05$ level are in bold type. Fit indices of models with aspiration-attainment gap (AAG) threshold of 0: general life satisfaction- $\chi^{2}(3)=1.311, p=.727$, comparative fit index $(\mathrm{CFI})=1.000$, root-meansquare error of approximation $($ RMSEA $)=.000$, standardized root-mean-square residual $($ SRMR $)=.008$, Bayesian information criterion $(\mathrm{BIC})=27,123.527 ;$ job satisfaction- $\chi^{2}(3)=5.099, p=.165, \mathrm{CFI}=.992, \mathrm{RMSEA}=.021, \mathrm{SRMR}=.021, \mathrm{BIC}=26,395.080 ;$ income satisfaction$\chi^{2}(3)=1.031, p=.794, \mathrm{CFI}=1.000, \mathrm{RMSEA}=.000, \mathrm{SRMR}=.006, \mathrm{BIC}=27,730.384$. Fit indices of models with AAG threshold of $|5|:$ general life satisfaction- $\chi^{2}(3)=2.086, p=.555, \mathrm{CFI}=1.000, \mathrm{RMSEA}=.000, \mathrm{SRMR}=.010, \mathrm{BIC}=26.568,184 ;$ job satisfaction- $-\chi^{2}(3)=5.384, p=.146$, $\mathrm{CFI}=.989, \mathrm{RMSEA}=.023, \mathrm{SRMR}=.023, \mathrm{BIC}=25,837.174$; income satisfaction $-\chi^{2}(3)=1.187, p=.756, \mathrm{CFI}=1.000, \mathrm{RMSEA}=.000$, SRMR $=.006, \mathrm{BIC}=27,162.963$. 


\section{Appendix H}

Unstandardized Coefficients of the Latent Growth Curve Models for Three Domains of Subjective Well-Being Regressed on the Aspiration-Attainment

Gap and Covariates (Model III)

\begin{tabular}{|c|c|c|c|c|c|c|c|c|c|c|c|c|c|c|c|c|c|c|}
\hline & \multicolumn{6}{|c|}{ General life satisfaction } & \multicolumn{6}{|c|}{ Job satisfaction } & \multicolumn{6}{|c|}{ Income satisfaction } \\
\hline & \multicolumn{2}{|c|}{ Threshold 0} & \multicolumn{4}{|c|}{ Threshold $+/-5$} & \multicolumn{2}{|c|}{ Threshold 0} & \multicolumn{4}{|c|}{ Threshold $+/-5$} & \multicolumn{3}{|c|}{ Threshold 0} & \multicolumn{3}{|c|}{ Threshold $+/-5$} \\
\hline & Coef. & $S E$ & $p$ & Coef. & $S E$ & $p$ & Coef. & $S E$ & $p$ & Coef. & $S E$ & $p$ & Coef. & $S E$ & $p$ & Coef. & $S E$ & $p$ \\
\hline \multicolumn{19}{|l|}{ Intercept $\left(\mathrm{t}_{0}\right)$ on } \\
\hline Underachievement & -0.188 & 0.135 & .163 & -0.203 & 0.136 & .137 & -0.350 & 0.176 & .046 & -0.415 & 0.183 & .023 & -0.623 & 0.250 & .013 & -0.916 & 0.252 & $<.001$ \\
\hline Overachievement & -0.436 & 0.185 & .018 & -0.404 & 0.239 & .091 & -0.651 & 0.263 & .013 & -0.594 & 0.330 & .072 & -0.493 & 0.328 & .133 & -0.917 & 0.411 & .026 \\
\hline Both groups combined ${ }^{a}$ & -0.270 & 0.124 & .030 & -0.256 & 0.130 & .050 & -0.452 & 0.168 & .007 & -0.461 & 0.178 & .009 & -0.576 & 0.232 & .013 & -0.918 & 0.238 & $<.001$ \\
\hline \multicolumn{19}{|l|}{ Intercept $\left(\mathrm{t}_{2}\right)$ on } \\
\hline Underachievement & -0.259 & 0.194 & .181 & -0.180 & 0.209 & .389 & -0.403 & 0.238 & .090 & -0.199 & 0.255 & .435 & -0.153 & 0.268 & .567 & -0.258 & 0.285 & .366 \\
\hline Overachievement & -0.212 & 0.178 & .235 & -0.102 & 0.215 & .634 & -0.245 & 0.305 & .422 & 0.098 & 0.322 & .768 & -0.170 & 0.360 & .636 & -0 & 0.421 & .655 \\
\hline \multicolumn{19}{|l|}{ Intercept $\left(\mathrm{t}_{0}\right)$ on } \\
\hline Conscientiousness & 0.094 & 0.041 & .022 & 0.100 & 0.041 & .014 & 0.095 & 0.061 & .123 & 0.100 & 0.060 & .094 & 0.109 & 0.091 & .231 & 0.110 & 0.089 & .218 \\
\hline Extraversion & 0.084 & 0.042 & .047 & 0.085 & 0.042 & .045 & 0.113 & 0.058 & .052 & 0.113 & 0.058 & .052 & -0.062 & 0.074 & .403 & -0.057 & 0.074 & .443 \\
\hline Agreeableness & 0.218 & 0.053 & $<.001$ & 0.215 & 0.053 & $<.001$ & 0.108 & 0.080 & .176 & 0.104 & 0.079 & .190 & 0.275 & 0.105 & .009 & 0.269 & 0.105 & .011 \\
\hline Openness & 0.082 & 0.049 & .094 & 0.080 & 0.049 & .104 & 0.029 & 0.076 & .700 & 0.033 & 0.075 & .661 & 0.161 & 0.103 & .118 & 0.162 & 0.102 & .112 \\
\hline Emotional Stability & 0.164 & 0.044 & $<.001$ & 0.169 & 0.045 & $<.001$ & 0.166 & 0.065 & .011 & 0.175 & 0.066 & .008 & 0.058 & 0.086 & .503 & 0.074 & 0.087 & .396 \\
\hline Parental SES & 0.002 & 0.004 & .603 & 0.002 & 0.004 & .551 & -0.004 & 0.007 & .520 & -0.004 & 0.007 & .531 & 0.019 & 0.008 & .018 & 0.019 & 0.008 & .015 \\
\hline Migration background & 0.247 & 0.126 & .050 & 0.240 & 0.125 & .055 & 0.042 & 0.192 & .826 & 0.028 & 0.192 & .884 & 0.118 & 0.258 & .649 & 0.114 & 0.257 & .656 \\
\hline Female & -0.082 & 0.095 & .385 & -0.070 & 0.095 & .462 & -0.170 & 0.140 & .225 & -0.158 & 0.140 & .257 & -0.148 & 0.191 & .438 & -0.077 & 0.192 & .687 \\
\hline Post-economic crisis recovery & -0.125 & 0.111 & .262 & -0.128 & 0.110 & .246 & -0.190 & 0.158 & .229 & -0.210 & 0.157 & .182 & -0.033 & 0.206 & .874 & -0.065 & 0.205 & .752 \\
\hline Pre-economic crisis & -0.325 & 0.119 & .006 & $-\mathbf{0 . 3 2 0}$ & 0.117 & .006 & -0.391 & 0.166 & .018 & -0.396 & 0.168 & .018 & -0.635 & 0.245 & .010 & -0.675 & 0.245 & .006 \\
\hline VET entry before 1 st interview & $\mathbf{0 . 3 3 5}$ & 0.105 & .001 & 0.342 & 0.104 & .001 & -0.339 & 0.302 & .262 & -0.352 & 0.303 & .246 & 0.360 & 0.339 & .288 & 0.302 & 0.337 & .371 \\
\hline \multicolumn{19}{|l|}{ Intercept $\left(\mathrm{t}_{2}\right)$ on } \\
\hline Conscientiousness & -0.004 & 0.055 & .945 & 0.002 & 0.055 & .969 & 0.113 & 0.086 & .192 & 0.124 & 0.086 & .151 & 0.241 & 0.096 & .012 & 0.240 & 0.096 & .012 \\
\hline Extraversion & 0.073 & 0.058 & .202 & 0.073 & 0.058 & .207 & 0.045 & 0.087 & .604 & 0.046 & 0.087 & .597 & -0.134 & 0.084 & .113 & -0.129 & 0.085 & .129 \\
\hline Agreeableness & 0.097 & 0.073 & .189 & 0.096 & 0.073 & .193 & 0.244 & 0.101 & .016 & 0.241 & 0.102 & .019 & 0.127 & 0.111 & .253 & 0.124 & 0.111 & .266 \\
\hline Openness & -0.018 & 0.067 & .784 & -0.025 & 0.067 & .713 & -0.017 & 0.095 & .858 & -0.030 & 0.094 & .753 & -0.046 & 0.102 & .655 & -0.047 & 0.102 & .649 \\
\hline Emotional Stability & 0.306 & 0.067 & $<.001$ & 0.306 & 0.068 & $<.001$ & 0.194 & 0.090 & .031 & 0.193 & 0.089 & .030 & 0.062 & 0.095 & .511 & 0.064 & 0.094 & .495 \\
\hline
\end{tabular}




\begin{tabular}{|c|c|c|c|c|c|c|c|c|c|c|c|c|c|c|c|c|c|c|}
\hline & \multicolumn{6}{|c|}{ General life satisfaction } & \multicolumn{6}{|c|}{ Job satisfaction } & \multicolumn{6}{|c|}{ Income satisfaction } \\
\hline & \multicolumn{2}{|c|}{ Threshold 0} & \multicolumn{4}{|c|}{ Threshold $+/-5$} & \multicolumn{2}{|c|}{ Threshold 0} & \multicolumn{4}{|c|}{ Threshold $+/-5$} & \multicolumn{3}{|c|}{ Threshold 0} & \multicolumn{3}{|c|}{ Threshold $+/-5$} \\
\hline & Coef. & $S E$ & $p$ & Coef. & $S E$ & $p$ & Coef. & $S E$ & $p$ & Coef. & $S E$ & $p$ & Coef. & $S E$ & $p$ & Coef. & $S E$ & $p$ \\
\hline \multicolumn{19}{|l|}{ Intercept $\left(\mathrm{t}_{2}\right)$ on } \\
\hline Parental SES & -0.005 & 0.006 & .370 & -0.004 & 0.006 & .466 & -0.029 & 0.008 & $<.001$ & $-\mathbf{0 . 0 2 7}$ & 0.008 & .001 & 0.023 & 0.009 & .009 & 0.023 & 0.009 & .010 \\
\hline Migration background & 0.130 & 0.172 & .449 & 0.143 & 0.174 & .411 & -0.319 & 0.237 & .179 & -0.276 & 0.241 & .253 & 0.235 & 0.301 & .435 & 0.245 & 0.306 & .424 \\
\hline Female & -0.035 & 0.135 & .794 & -0.030 & 0.136 & .826 & -0.264 & 0.185 & .153 & -0.265 & 0.185 & .153 & -0.085 & 0.215 & .693 & -0.063 & 0.216 & .770 \\
\hline Post-crisis recovery & -0.366 & 0.171 & .032 & -0.353 & 0.170 & .038 & -0.230 & 0.210 & .273 & -0.196 & 0.208 & .346 & -0.395 & 0.243 & .104 & -0.411 & 0.242 & .090 \\
\hline Pre-economic crisis & -0.507 & 0.166 & .002 & -0.497 & 0.165 & .003 & -0.351 & 0.252 & .164 & -0.341 & 0.251 & .174 & -1.010 & 0.274 & $<.001$ & -0.996 & 0.275 & $<.001$ \\
\hline VET entry before & -0.142 & 0.169 & .401 & -0.114 & 0.171 & .506 & -0.241 & 0.227 & .288 & -0.183 & 0.226 & .418 & 0.168 & 0.252 & .504 & 0.152 & 0.251 & .545 \\
\hline \multicolumn{19}{|l|}{ Linear slope on } \\
\hline Underachievement & -0.035 & 0.114 & .756 & 0.011 & 0.120 & .926 & -0.026 & 0.134 & .846 & 0.108 & 0.141 & .445 & 0.235 & 0.167 & .160 & 0.329 & 0.176 & .061 \\
\hline Overachievement & 0.112 & 0.113 & .320 & 0.151 & 0.134 & .259 & 0.203 & 0.195 & .299 & 0.346 & 0.224 & .123 & 0.161 & 0.198 & .416 & 0.365 & 0.222 & .101 \\
\hline Both groups combined ${ }^{a}$ & 0.013 & 0.096 & .889 & 0.049 & 0.102 & .629 & 0.052 & 0.127 & .682 & 0.185 & 0.131 & 157 & 0.207 & 0.150 & .168 & 0.337 & 0.156 & .031 \\
\hline \multicolumn{19}{|l|}{ Linear slope on } \\
\hline Consci & -0.049 & 0.032 & .129 & -0.049 & 0.032 & .128 & 0.009 & 0.052 & .860 & 0.012 & 0.051 & .820 & 0.066 & 0.059 & .261 & 0.065 & 0.058 & .262 \\
\hline Extraversion & -0.006 & 0.033 & .867 & -0.006 & 0.033 & .856 & -0.034 & 0.049 & .483 & -0.033 & 0.048 & .491 & -0.036 & 0.049 & .460 & -0.036 & 0.049 & .458 \\
\hline Agreeableness & -0.061 & 0.043 & .159 & -0.060 & 0.043 & .163 & 0.068 & 0.061 & .264 & 0.068 & 0.061 & .264 & -0.074 & 0.067 & .267 & -0.073 & 0.067 & .275 \\
\hline Openness & -0.050 & 0.040 & .210 & -0.052 & 0.040 & .187 & -0.023 & 0.059 & .697 & -0.031 & 0.058 & .594 & -0.103 & 0.065 & .110 & -0.104 & 0.064 & .103 \\
\hline Emotional & 0.071 & 0.040 & .075 & 0.068 & 0.040 & .087 & 0.014 & 0.053 & .789 & 0.009 & 0.052 & .866 & 0.002 & 0.056 & .969 & -0.005 & 0.056 & .934 \\
\hline Parental SES & -0.004 & 0.003 & .295 & -0.003 & 0.003 & .340 & -0.012 & 0.005 & .015 & -0.011 & 0.005 & .024 & 0.002 & 0.005 & .672 & 0.002 & 0.006 & 699 \\
\hline Migration background & -0.058 & 0.106 & .583 & -0.048 & 0.107 & .652 & -0.181 & 0.147 & .220 & -0.152 & 0.149 & .307 & 0.059 & 0.179 & .744 & 0.065 & 0.181 & .719 \\
\hline Female & 0.024 & 0.079 & .766 & 0.020 & 0.080 & .801 & -0.047 & 0.110 & .669 & -0.053 & 0.110 & .627 & 0.032 & & .807 & 0.007 & 0.130 & .955 \\
\hline Post-economi & -0.121 & 0.098 & .216 & -0.112 & 0.097 & .248 & -0.020 & 0.127 & .875 & 0.007 & 0.127 & .956 & -0.181 & 0.145 & .214 & -0.173 & 0.145 & .234 \\
\hline Pre-economic & -0.091 & 0.100 & .360 & -0.088 & 0.099 & .371 & 0.020 & 0.144 & .890 & 0.027 & 0.145 & .850 & -0.188 & 0.159 & .238 & -0.160 & 0.158 & .310 \\
\hline VET entry before 1 st in & -0.238 & 0.100 & .017 & -0.228 & 0.100 & .023 & 0.049 & 0.210 & .816 & 0.084 & 0.209 & .688 & -0.096 & 0.222 & .667 & -0.075 & 0.221 & .733 \\
\hline \multicolumn{19}{|l|}{ Intercept-slope } \\
\hline Covariance $\left(\mathrm{t}_{0}\right)$ & -0.185 & 0.108 & .088 & -0.179 & 0.135 & .185 & -0.590 & 0.284 & .038 & -0.542 & 0.291 & .062 & -1.067 & 0.353 & .002 & -1.001 & 0.362 & .006 \\
\hline Covariance $\left(\mathrm{t}_{2}\right)$ & 0.284 & 0.166 & .087 & 0.282 & 0.165 & .088 & 0.433 & 0.288 & .133 & 0.423 & 0.293 & .149 & 0.498 & 0.339 & .142 & 0.512 & 0.342 & .135 \\
\hline \multicolumn{19}{|l|}{ Means } \\
\hline Under & 0.347 & 0.016 & .001 & 0.289 & 0.015 & $<.001$ & 0.347 & 0.016 &. .001 & 0.288 & 0.015 & .001 & 0.351 & 0.016 & .001 & 0.294 & 0.015 & $<.001$ \\
\hline Overachievement & 0.152 & 0.013 & <.001 & 0.096 & 0.011 & $<.001$ & 0.151 & 0.013 & $<.001$ & 0.096 & 0.011 & $<.001$ & 0.152 & 0.013 & $<.001$ & 0.097 & 0.011 & $<.001$ \\
\hline
\end{tabular}




\begin{tabular}{|c|c|c|c|c|c|c|c|c|c|c|c|c|c|c|c|c|c|c|}
\hline & \multicolumn{6}{|c|}{ General life satisfaction } & \multicolumn{6}{|c|}{ Job satisfaction } & \multicolumn{6}{|c|}{ Income satisfaction } \\
\hline & \multicolumn{2}{|c|}{ Threshold 0} & \multicolumn{4}{|c|}{ Threshold $+/-5$} & \multicolumn{2}{|c|}{ Threshold 0} & \multicolumn{4}{|c|}{ Threshold $+/-5$} & \multicolumn{3}{|c|}{ Threshold 0} & \multicolumn{3}{|c|}{ Threshold $+/-5$} \\
\hline & Coef. & $S E$ & $p$ & Coef. & $S E$ & $p$ & Coef. & $S E$ & $p$ & Coef. & $S E$ & $p$ & Coef. & $S E$ & $p$ & Coef. & $S E$ & $p$ \\
\hline \multicolumn{19}{|l|}{ Means } \\
\hline Conscientiousness & 4.951 & 0.028 & $<.001$ & 4.951 & 0.028 & $<.001$ & 4.951 & 0.028 & $<.001$ & 4.951 & 0.028 & $<.001$ & 4.951 & 0.028 & $<.001$ & 4.951 & 0.028 & $<.001$ \\
\hline Extraversion & 4.900 & 0.032 & $<.001$ & 4.900 & 0.032 & $<.001$ & 4.900 & 0.032 & $<.001$ & 4.901 & 0.032 & $<.001$ & 4.900 & 0.032 & $<.001$ & 4.900 & 0.032 & $<.001$ \\
\hline Agreeableness & 5.351 & 0.024 & $<.001$ & 5.351 & 0.024 & $<.001$ & 5.351 & 0.024 & $<.001$ & 5.351 & 0.024 & $<.001$ & 5.351 & 0.024 & $<.001$ & 5.351 & 0.024 & $<.001$ \\
\hline Openness & 4.638 & 0.026 & $<.001$ & 4.639 & 0.026 & $<.001$ & 4.638 & 0.026 & $<.001$ & 4.639 & 0.026 & $<.001$ & 4.638 & 0.026 & $<.001$ & 4.639 & 0.026 & $<.001$ \\
\hline Emotional Stability & 4.047 & 0.029 & $<.001$ & 4.047 & 0.029 & $<.001$ & 4.048 & 0.029 & $<.001$ & 4.047 & 0.029 & $<.001$ & 4.047 & 0.029 & $<.001$ & 4.047 & 0.029 & $<.001$ \\
\hline Parental SES & 43.180 & 1.111 & $<.001$ & 42.977 & 1.127 & $<.001$ & 43.049 & 1.093 & $<.001$ & 42.839 & 1.113 & $<.001$ & 43.114 & 1.107 & $<.001$ & 42.928 & 1.120 & $<.001$ \\
\hline Migration background & 0.189 & 0.010 & $<.001$ & 0.189 & 0.010 & $<.001$ & 0.189 & 0.010 & $<.001$ & 0.189 & 0.010 & $<.001$ & 0.189 & 0.010 & $<$. & 0.189 & 0.010 & $<.001$ \\
\hline Female & 0.452 & 0.013 & $<.001$ & 0.452 & 0.013 & $<.001$ & 0.452 & 0.013 & $<.001$ & 0.452 & 0.013 & $<.001$ & 0.452 & 0.013 & $<.001$ & 0.452 & 0.013 & $<.001$ \\
\hline isis recovery & 0.339 & 0.012 & $<.001$ & 0.339 & 0.012 & $<.001$ & 0.339 & 0.012 & $<.001$ & 0.339 & 0.012 & $<.001$ & 0.339 & 0.012 & $<.001$ & 0.339 & 0.012 & $<.001$ \\
\hline Pre-eco & 0.213 & 0.010 & $<.001$ & 0.213 & 0.010 & $<.001$ & 0.213 & 0.010 & $<.001$ & 0.213 & 0.010 & $<.0$ & 0.2 & 0.0 & $<.001$ & 0. & 0.010 & $<.001$ \\
\hline VET entry & 0.233 & 0.011 & $<.001$ & 0.233 & 0.011 & $<.001$ & 0.233 & 0.011 & $<.001$ & 0.233 & 0.011 & $<.001$ & 0.233 & 0.011 & $<.001$ & 0.233 & 0.011 & $<.001$ \\
\hline \multicolumn{19}{|l|}{ Intercepts } \\
\hline Intercept $\left(\mathrm{t}_{0}\right)$ & 4.689 & 0.45 & $<.001$ & 4.610 & 0.453 & $<.001$ & 6.193 & 0.6 & $<.001$ & 6.091 & 0.627 & $<.001$ & 3.080 & 0.828 & $<.001$ & 3.066 & 0.816 & $<.001$ \\
\hline Inter & 6.001 & 0.62 & $<.001$ & 5.890 & 0.615 & $<.001$ & 202 & 0.764 & $<.001$ & 5.984 & 0.754 & $<.001$ & 3.866 & 0.887 & $<.001$ & 3.872 & 0.881 & $<.001$ \\
\hline Linear slope & 0.656 & 0.376 & .081 & 0.640 & 0.372 & .086 & 0.004 & 0.497 & .993 & -0.054 & 0.490 & .913 & 0.393 & 0.537 & .465 & 0.403 & 0.533 & .450 \\
\hline \multicolumn{19}{|l|}{ Variances } \\
\hline Underachievement & 0.224 & 0.006 & $<.001$ & 0.201 & 0.007 & $<.001$ & 0.223 & 0.006 & $<.001$ & 0.200 & 0.007 & $<.001$ & 0.223 & 0.006 & $<.001$ & 0.200 & 0.007 & $<.001$ \\
\hline Overachievement & 0.125 & 0.009 & $<.001$ & 0.083 & 0.009 & $<.001$ & 0.125 & 0.009 & $<.001$ & 0.083 & 0.009 & $<.001$ & 0.125 & 0.009 & $<.001$ & 0.083 & 0.009 & $<.001$ \\
\hline Conscientiousness & 1.215 & 0.042 & $<.001$ & 1.215 & 0.042 & $<.001$ & 1.215 & 0.042 & $<.001$ & 1.215 & 0.042 & $<.001$ & 1.215 & 0.042 & $<.001$ & 1.215 & 0.042 & $<.001$ \\
\hline Extraversion & 1.552 & 0.052 & $<.001$ & 1.552 & 0.052 & $<.001$ & 1.552 & 0.052 & $<.001$ & 1.552 & 0.052 & $<.001$ & 1.552 & 0.052 & $<.001$ & 1.552 & 0.052 & $<.001$ \\
\hline Agreeableness & 0.856 & 0.032 & $<.001$ & 0.856 & 0.032 & $<.001$ & 0.856 & 0.032 & $<.001$ & 0.856 & 0.032 & $<.001$ & 0.856 & 0.032 & $<.001$ & 0.856 & 0.032 & $<.001$ \\
\hline Openness & 0.993 & 0.033 & $<.001$ & 0.993 & 0.033 & $<.001$ & 0.993 & 0.033 & $<.001$ & 0.993 & 0.033 & $<.001$ & 0.993 & 0.033 & $<.001$ & 0.993 & 0.033 & $<.001$ \\
\hline Emotional & 1.309 & 0.044 & $<.001$ & 1.309 & 0.044 & $<.001$ & 1.309 & 0.044 & $<.001$ & 1.309 & 0.044 & $<.001$ & 1.309 & 0.044 & $<.001$ & 1.309 & 0.044 & $<.001$ \\
\hline Parental SES & 347.583 & 14.889 & $<.001$ & 347.121 & 14.505 & $<.001$ & 348.672 & 14.728 & $<.001$ & 347.736 & 14.365 & $<.001$ & 346.969 & 14.804 & $<.001$ & 346.421 & 14.453 & $<.001$ \\
\hline Migration background & 0.154 & 0.006 & $<.001$ & 0.154 & 0.006 & $<.001$ & 0.154 & 0.006 & $<.001$ & 0.154 & 0.006 & $<.001$ & 0.154 & 0.006 & $<.001$ & 0.154 & 0.006 & $<.001$ \\
\hline Female & 0.248 & 0.001 & $<.001$ & 0.248 & 0.001 & $<.001$ & 0.248 & 0.001 & $<.001$ & 0.248 & 0.001 & $<.001$ & 0.248 & 0.001 & $<.001$ & 0.248 & 0.001 & $<.001$ \\
\hline Post-economic crisis recovery & 0.224 & 0.004 & $<.001$ & 0.224 & 0.004 & $<.001$ & 0.224 & 0.004 & $<.001$ & 0.224 & 0.004 & $<.001$ & 0.224 & 0.004 & $<.001$ & 0.224 & 0.004 & $<.001$ \\
\hline Pre-economic crisis & 0.168 & 0.006 & $<.001$ & 0.168 & 0.006 & $<.001$ & 0.168 & 0.006 & $<.001$ & 0.168 & 0.006 & $<.001$ & 0.168 & 0.006 & $<.001$ & 0.168 & 0.006 & $<.001$ \\
\hline VET entry before 1 st interview & 0.179 & 0.006 & $<.001$ & 0.179 & 0.006 & $<.001$ & 0.179 & 0.006 & $<.001$ & 0.179 & 0.006 & $<.001$ & 0.179 & 0.006 & $<.001$ & 0.179 & 0.006 & $<.001$ \\
\hline
\end{tabular}




\begin{tabular}{|c|c|c|c|c|c|c|c|c|c|c|c|c|c|c|c|c|c|c|}
\hline & \multicolumn{6}{|c|}{ General life satisfaction } & \multicolumn{6}{|c|}{ Job satisfaction } & \multicolumn{6}{|c|}{ Income satisfaction } \\
\hline & \multicolumn{2}{|c|}{ Threshold 0} & \multicolumn{4}{|c|}{ Threshold $+/-5$} & \multicolumn{2}{|c|}{ Threshold 0} & \multicolumn{4}{|c|}{ Threshold $+/-5$} & \multicolumn{3}{|c|}{ Threshold 0} & \multicolumn{3}{|c|}{ Threshold $+/-5$} \\
\hline & Coef. & $S E$ & $p$ & Coef. & $S E$ & $p$ & Coef. & $S E$ & $p$ & Coef. & $S E$ & $p$ & Coef. & $S E$ & $p$ & Coef. & $S E$ & $p$ \\
\hline \multicolumn{19}{|c|}{ Residual variances } \\
\hline Satisfaction $\mathrm{t}_{0}$ & 1.202 & 0.206 & $<.001$ & 1.211 & 0.224 & $<.001$ & 0.974 & 0.442 & .028 & 1.037 & 0.452 & .022 & 1.874 & 0.522 & $<.001$ & 1.905 & 0.528 & $<.001$ \\
\hline Satisfaction $\mathrm{t}_{1}$ & 1.262 & 0.137 & $<.001$ & 1.266 & 0.137 & $<.001$ & 2.286 & 0.244 & $<.001$ & 2.284 & 0.245 & $<.001$ & 2.638 & 0.243 & $<.001$ & 2.646 & 0.243 & $<.001$ \\
\hline Satisfaction $t_{2}$ & 1.127 & 0.228 & $<.001$ & 1.130 & 0.264 & $<.001$ & 1.716 & 0.441 & $<.001$ & 1.738 & 0.447 & $<.001$ & 1.745 & 0.507 & .001 & 1.737 & 0.509 & .001 \\
\hline Intercept $\left(\mathrm{t}_{0}\right)$ & 1.137 & 0.217 & $<.001$ & 1.133 & 0.222 & $<.001$ & 2.363 & 0.451 & $<.001$ & 2.312 & 0.453 & $<.001$ & 5.079 & 0.558 & $<.001$ & 4.939 & 0.568 & $<.001$ \\
\hline Intercept $\left(\mathrm{t}_{2}\right)$ & 1.336 & 0.298 & $<.001$ & 1.339 & 0.297 & $<.001$ & 2.047 & 0.472 & $<.001$ & 2.074 & 0.473 & $<.001$ & 3.942 & 0.554 & $<.001$ & 3.960 & 0.560 & $<.001$ \\
\hline Linear slope & 0.234 & 0.069 & .001 & 0.230 & 0.123 & .060 & 0.511 & 0.239 & .032 & 0.482 & 0.246 & .050 & 0.783 & 0.290 & .007 & 0.756 & 0.296 & .011 \\
\hline
\end{tabular}

Note. VET = vocational education and training. $N=1,536$. Regression coefficients and intercept-slope covariances significant at the $p<.05$ level are in bold type. Fit indices of the models with aspiration-attainment gap (AAG) threshold of 0: general life satisfaction- $-\chi^{2}(14)=4.485, p=.992$, comparative fit index $(\mathrm{CFI})=1.000$, root-mean-square error of approximation $(\mathrm{RMSEA})=.000$, standardized root-mean-square residual $(\mathrm{SRMR})=.005$, Bayesian information criterion $(\mathrm{BIC})=64,039.694$; job satisfaction- $-\chi^{2}(14)=21.242, p=.096, \mathrm{CFI}=.994, \mathrm{RMSEA}=.018, \mathrm{SRMR}=.015$, $\mathrm{BIC}=63,929.135 ;$ income satisfaction $-\chi^{2}(14)=6.310, p=.958, \mathrm{CFI}=1.000, \mathrm{RMSEA}=.000, \mathrm{SRMR}=.014, \mathrm{BIC}=65,265.732$. Fit indices of the models with AAG threshold of $|5|:$ general life satisfaction- $-\chi^{2}(14)=5.370, p=.980, \mathrm{CFI}=1.000, \mathrm{RMSEA}=.000, \mathrm{SRMR}=.006, \mathrm{BIC}=63,039.694$; job satisfaction- $\chi^{2}(14)=19.564, p=.145, \mathrm{CFI}=.995, \mathrm{RMSEA}=.016, \mathrm{SRMR}=.015, \mathrm{BIC}=63,377.329 ;$ income satisfaction- $\chi^{2}(14)=6.252$, $p=.960, \mathrm{CFI}=1.000, \mathrm{RMSEA}=.000, \mathrm{SRMR}=.014, \mathrm{BIC}=64,702.880$.

${ }^{\text {a }}$ For further analyses, which we briefly address only in the Discussion section of our paper, we combined under- and overachievement in one group. 